\title{
Synaptic Variability Introduces State-Dependent Modulation of Excitatory Spinal Cord Synapses
}

\author{
David Parker \\ Department of Physiology, Development and Neuroscience, University of Cambridge, Cambridge CB2 3DY, UK \\ Correspondence should be addressed to David Parker; djp27@cam.ac.uk
}

Received 9 March 2015; Accepted 30 May 2015

Academic Editor: Małgorzata Kossut

Copyright (C) 2015 David Parker. This is an open access article distributed under the Creative Commons Attribution License, which permits unrestricted use, distribution, and reproduction in any medium, provided the original work is properly cited.

\begin{abstract}
The relevance of neuronal and synaptic variability remains unclear. Cellular and synaptic plasticity and neuromodulation are also variable. This could reflect state-dependent effects caused by the variable initial cellular or synaptic properties or direct variability in plasticity-inducing mechanisms. This study has examined state-dependent influences on synaptic plasticity at connections between excitatory interneurons (EIN) and motor neurons in the lamprey spinal cord. State-dependent effects were examined by correlating initial synaptic properties with the substance P-mediated plasticity of low frequency-evoked EPSPs and the reduction of the EPSP depression over spike trains (metaplasticity). The low frequency EPSP potentiation reflected an interaction between the potentiation of NMDA responses and the release probability. The release probability introduced a variable state-dependent subtractive influence on the postsynaptic NMDA-dependent potentiation. The metaplasticity was also state-dependent: it was greater at connections with smaller available vesicle pools and high initial release probabilities. This was supported by the significant reduction in the number of connections showing metaplasticity when the release probability was reduced by high $\mathrm{Mg}^{2+}$ Ringer. Initial synaptic properties thus introduce state-dependent influences that affect the potential for plasticity. Understanding these conditions will be as important as understanding the subsequent changes.
\end{abstract}

\section{Introduction}

Variability is a feature of healthy physiological systems. Meanwhile, significant variability is recognized within neuronal and synaptic populations [1-11]; its relevance remains unclear [10,11]. Plasticity effects are also variable [12-21]. This could reflect differences in plasticity-inducing mechanisms (e.g., second messenger pathways) or state-dependent effects caused by differences in initial cellular or synaptic properties [22].

This study has examined state-dependent influences on synaptic plasticity in the lamprey spinal cord by making paired recordings from connections made by glutamatergic excitatory interneurons (EINs) onto motor neurons. This connection exhibits marked variability and consists of functionally different subgroups [23]. The EINs provide the excitatory drive to the locomotor network [24] and are thus essential network components. Substance P presynaptically and postsynaptically modulates EIN inputs to motor neurons through changes in gene expression and synaptic ultrastructure [25-28]. Functionally, substance P potentiates low frequency-evoked EPSP amplitudes [29] and reduces depression during spike trains [28]. However, as with the basic properties of the connection [23], both forms of plasticity vary [25, 2729].

The synaptic effects of substance P were initially examined on TTX-resistant miniature EPSPs, spontaneous EPSPs, and locomotor-related depolarizations [27]. These approaches are routinely used to examine synaptic interactions and modulation in spinal networks. However, they are indirect and do not identify changes at specific synapses and may not even reflect synaptic effects. Synaptic potentiation occurred in over $90 \%$ of these experiments $[27,30]$. However, when monosynaptic EIN-evoked EPSPs were examined using paired recordings, potentiation occurred in $60-70 \%$ of experiments ([29]; see also [12, 17, 31]). This disparity could be caused by the activation of different types of neurons with different sensitivities to substance $\mathrm{P}$ when indirect 
approaches are used or that only a proportion of EINs is subject to modulation and significant effects are more likely when inputs are evoked simultaneously from multiple cells.

Small sample sizes prevented the variable plasticity of EINs inputs from being examined previously $[25,27,28]$. This study has used a larger sample of paired recordings to examine the influence of initial synaptic properties on plasticity. The results suggest that initial properties introduced statedependent influences that affected the potential for synaptic plasticity.

\section{Materials and Methods}

Adult male and female lampreys (Lampetra fluviatilis) were obtained from commercial suppliers (Baitbox, Grimsby, UK). Animals were anaesthetized with MS-222 and the spinal cord and notochord were removed. A piece of spinal cord $(1-2 \mathrm{~cm})$ was isolated from the notochord and placed ventral side up in a Sylgard-lined chamber where it was superfused with Ringer containing (in mM): $138 \mathrm{NaCl}, 2.1 \mathrm{KCl}, 1.8 \mathrm{CaCl}_{2}, 1.2 \mathrm{MgCl}_{2}, 4$ glucose, 2 HEPES, and $0.5 \mathrm{~L}$-glutamine. The Ringer was bubbled with $\mathrm{O}_{2}$ and the $\mathrm{pH}$ adjusted to 7.4 with $1 \mathrm{M} \mathrm{NaOH}$. The experimental chamber was kept at a temperature of $10-12^{\circ} \mathrm{C}$.

Paired recordings were made from excitatory interneurons (EINs) and motor neurons using thin walled micropipettes filled with $3 \mathrm{M}$ potassium acetate and $0.1 \mathrm{M}$ potassium chloride to reduce tip potentials. Motor neurons were identified by recording orthodromic extracellular spikes in a ventral root following current injection into their somata. EINs were identified by their ability to elicit monosynaptic EPSPs in motor neurons (see [24]). Monosynaptic inputs were identified by their reliability and constant latency following presynaptic stimulation at $20 \mathrm{~Hz}$ [32]. While there is no evidence for regional differences in the EINs, to reduce potential location-dependent variability, experiments were only performed in the rostral trunk region just caudal to the last gill, and all EINs were recorded 1 segment rostral to the motor neuron. An Axoclamp 2A amplifier (Axon Instruments, California) was used for voltage recording and current injection. The motor neuron membrane potential was kept at $-70 \mathrm{mV}$ by injecting depolarizing or hyperpolarizing current using single electrode discontinuous current clamp (switching rate: $2 \mathrm{KHz}$ ). This was necessary to ensure that effects within and between experiments were not simply due to differences in membrane potential. While membrane potential differences could provide a physiologically relevant state-dependent variable, if it was not controlled across experiments, it would be impossible to separate synaptic variability from membrane potential variability [23]. The output of the sample-and-hold amplifier in the DCC circuit was monitored to ensure complete settling before voltage measurement. Data were acquired, stored, and analysed on computer using an analogue-to-digital interface (Digidata 1200, Axon Instruments, California) and Axon Instruments software (pCLAMP 8).

EIN action potentials were evoked by injecting $1 \mathrm{~ms}$ depolarizing current pulses of $0.5-3 \mathrm{nA}$. Low frequency-evoked EPSPs were examined by stimulating the EINs at $0.1 \mathrm{~Hz}$.
EPSPs were averaged ( $n=10$ sweeps) in control and after substance $\mathrm{P}$ application ( $1 \mu \mathrm{M}$ for $10 \mathrm{~min}$; no activity-dependent plasticity occurs at this stimulation frequency). Effects over spike trains were examined by stimulating the EINs at $20 \mathrm{~Hz}$ for $1 \mathrm{~s}$. The spike trains were evoked at $20 \mathrm{~s}$ intervals and averaged $(n=10)$ in control and after substance P application. Low frequency or train effects were not necessarily studied in all connections. Where spike trains were examined the initial EPSP in the spike train was used as a measure of the low frequency-evoked EPSP amplitude. While EIN stimulation at $20 \mathrm{~Hz}$ is a physiologically relevant frequency [33] over which substance P-evoked plasticity occurs [28], EINs only spike up to five times during fictive locomotion [34]. In contrast to previous analyses $[25,28]$, effects were only examined over the first five spikes to examine effects over the physiologically relevant range. The $1 \mathrm{~s}$ spike trains were used as they can be useful in providing insight into plasticity mechanisms (e.g., vesicle numbers; see below) while allowing effects over the physiological range to be selected.

EPSP amplitudes were measured as the peak amplitude above the baseline immediately preceding the presynaptic action potential. No attempt was made to correct for the effects of EPSP summation during spike trains [35] as there is usually little summation [28] and correcting for it did not significantly change measured EPSP amplitudes or their activity-dependent plasticity [23]. The initial EPSP amplitude and its change in substance $\mathrm{P}\left(\mathrm{EPSP}_{\text {Subs } \mathrm{P}} / \mathrm{EPSP}_{\mathrm{Control}}\right)$, the paired pulse $(\mathrm{PP})$ plasticity $\left(\mathrm{EPSP}_{2} / \mathrm{EPSP}_{1}\right)$, and plasticity over the 2 nd to 5 th spikes in the trains $\left(\mathrm{EPSP}_{\operatorname{Train}_{2-5}} / \mathrm{EPSP}_{1}\right)$ were measured $[25,28]$.

The release probability was determined directly in previous analyses using a variance-mean analysis [23, 25]. However, this requires relatively long-term recordings, which are rare [25]. The paired pulse ( $\mathrm{PP}$ ) ratio is routinely used to measure release probability, but the relationship between these effects is not simple as the PP ratio can be influenced by various presynaptic and postsynaptic effects [36-39]. Data from previous variance-mean analyses was used to examine the relationship between the PP ratio and the release probability ([23, 25]; Parker, unpublished data). There was a significant negative correlation $\left(r^{2}=0.77, n=18, p<0.05\right.$; Figure 1(a)), which suggested that the PP ratio could be used to estimate the release probability.

The available synaptic vesicle pool was estimated from the depression of the EPSP over spike trains using the model of Wang and Zucker ([40]; see Figure 1(b)). This estimates the number of available vesicles from the initial and final PSP amplitude and the rate of depression (see Figure 1(b); [23]):

$$
N_{\text {ves }}=\frac{V_{o}^{2} \tau d}{q\left(V_{o}-V_{\infty}\right)},
$$

where $V_{o}$ is the initial EPSP amplitude, $\tau d$ is the inverse rate constant of EPSP decay (expressed as the number of presynaptic spikes needed for the EPSP to drop to $1 / e$ of the initial value), $q$ is the mean quantal amplitude (set at $0.1 \mathrm{mV}$; [23]), and $V_{\infty}$ is the EPSP amplitude at the plateau level of depression. However, not all connections depress [23], and in those that do depression to $1 / e$ of the initial value often does not 


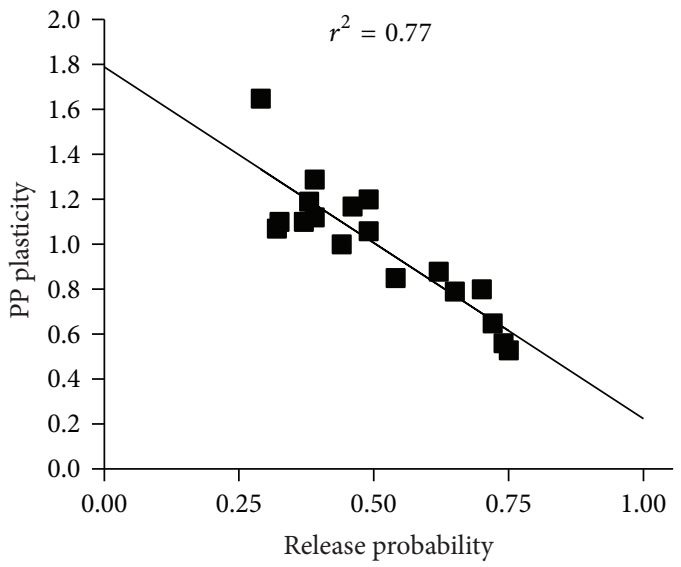

(a)

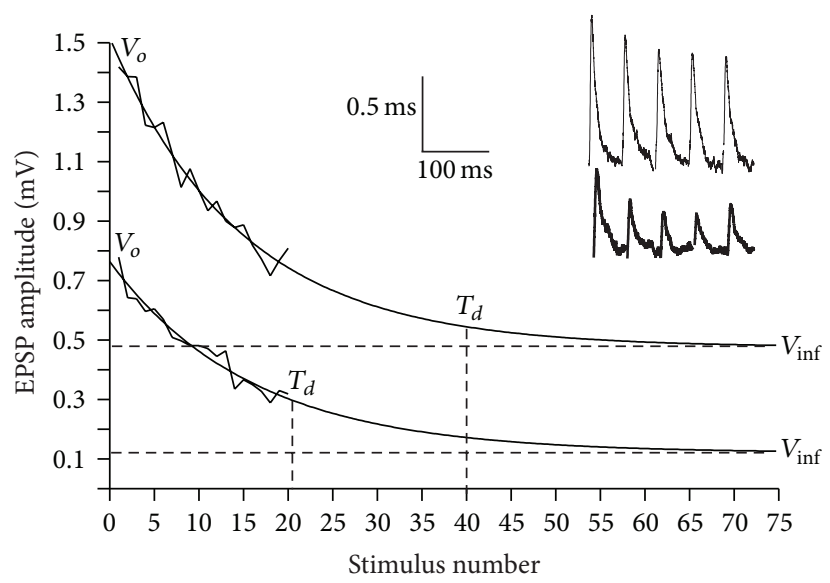

(b)

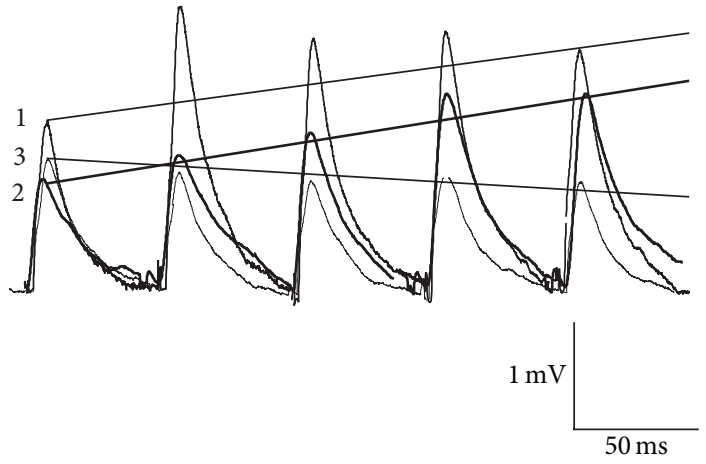

(c)

FIGURE 1: (a) Graph showing the significant relationship between the PP ratio and release probability using data from previous variancemean analyses (see Section 2). (b) Analysis of the estimated available vesicle pool from the depression of connections. The inset shows two synapses that were depressed from different initial EPSP amplitudes. (c) Traces showing different forms of activity-dependent plasticity. Metaplasticity (1) is defined as reduced depression or increased facilitation from an increased initial EPSP amplitude; release probabilitydependent facilitation (2; thick line) as facilitation from a reduced initial EPSP amplitude; and release probability-dependent depression (3) as depression from a larger initial EPSP amplitudes.

occur even over longer spike trains. This is probably due to the presence of simultaneous activity-dependent replenishment [41]. As a result, the extrapolated exponential depression calculated using the initial 2-3 EPSPs in the train was used to determine $\tau d$ and $V_{\infty}$ to allow approximation of the vesicle pool [23]. Any replenishment would reduce the rate of rundown and thus cause overestimation of the initial vesicle pool.

Substance $\mathrm{P}(1 \mu \mathrm{M})$ was applied once to each piece of spinal cord for $10 \mathrm{~min}$. As it can evoke depolarizing oscillations and increased spontaneous synaptic inputs in motor neurons [30], synaptic inputs were only evoked after these effects had decayed ( 2-5 min; [30]). $N$ numbers in the text refer to the number of connections examined (only one synapse was examined in each piece of spinal cord). With the exception of the variance-mean data (Figure 1(a)), connections here were not used in previous analyses [25, 28,29]. This was to ensure that all experiments were performed in the same species and under the same conditions. Stricter criteria for the synaptic changes were also used than in previous analyses $[25,28]$. To be classed as potentiated or reduced, the low frequency-evoked EPSP amplitude had to be at least 110\% or $90 \%$ of control, respectively, and for metaplasticity the initial EPSP had to be potentiated to at least $110 \%$ of control, and $\operatorname{Train}_{2-5}$ plasticity had to increase to at least $110 \%$ of control (1 on Figure 1(c)). These limits were imposed to focus on connections that showed relatively strong effects to help identify state-dependent changes associated with these forms of plasticity [10]. This resulted in the removal of 6 connections from the low frequency-evoked EPSP analysis and 10 from the spike train analysis. Statistical significance was examined using two-tailed paired or independent $t$-tests, Chi square, or one-way analysis of variance (ANOVA). When an ANOVA was used a Tukey test was used for post hoc analysis between groups. All values given refer to mean \pm SEM.

\section{Results}

While they will be functionally related, for simplicity the influence of initial synaptic properties on the modulation of low frequency and train-evoked EPSPs will be presented separately. 


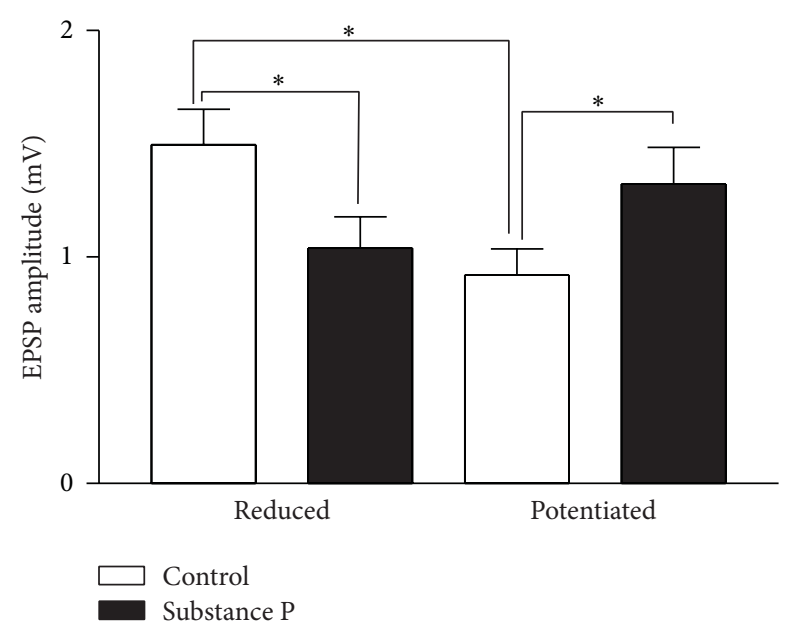

(ai)

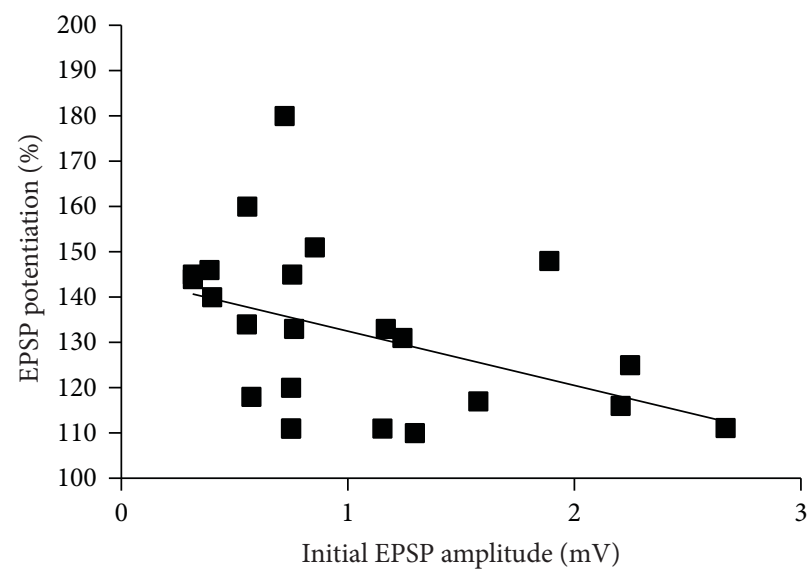

(b)

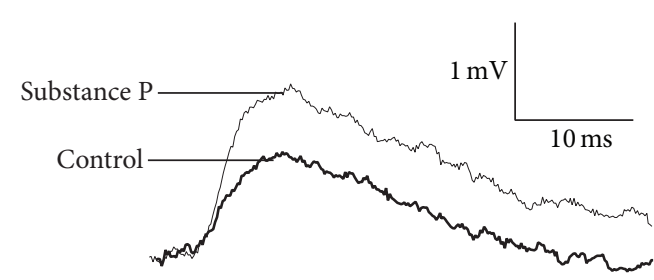

(aii)

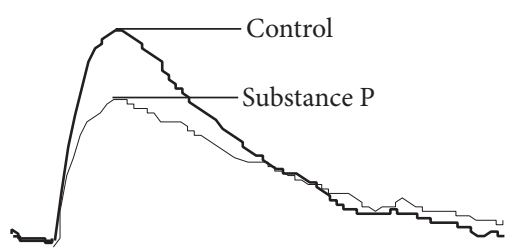

(aiii)

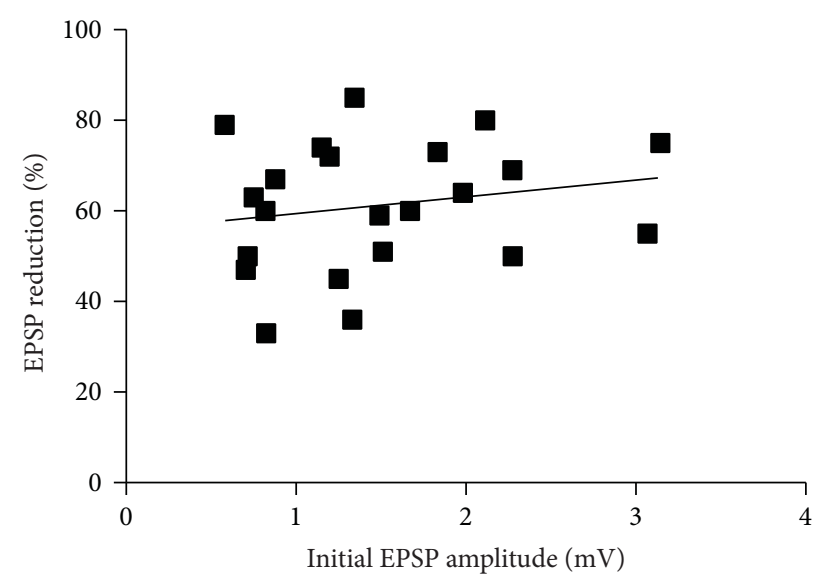

(c)

FIGURE 2: (ai) Graph showing the amplitude of the initial EPSP at connections that were potentiated or reduced by substance P. On this and other graphs, the asterisk indicates a statistically significant difference. Sample traces show connections where substance P potentiated (aii) or reduced (aiii) the initial EPSP amplitude. (b) Graph showing the significant negative relationship between the initial EPSP amplitude and the magnitude of the EPSP potentiation. (c) Graph showing the lack of a significant relationship between the initial EPSP amplitude and the magnitude of the EPSP reduction.

3.1. Effects on Low Frequency-Evoked EPSPs. The substance Pmediated potentiation of low frequency-evoked EPSP amplitudes occurred in 22 of 44 connections (50\%), a smaller proportion than that seen previously in a smaller sample size (70\%; [29]). EIN-evoked EPSP amplitudes in motor neurons vary markedly (range 0.2 to $\sim 4 \mathrm{mV}$; [23]). At potentiated connections, the amplitude of low frequency-evoked EPSPs was increased from $0.92 \pm 0.11 \mathrm{mV}$ to $1.32 \pm 0.16 \mathrm{mV}$ ( $p<$ $0.05 ; n=22$; Figure 2(ai)), and at connections where the EPSP amplitude was reduced, it was from $1.49 \pm 0.15 \mathrm{mV}$ to $1.04 \pm 0.14 \mathrm{mV}(p<0.05, n=22$; Figures 2(ai)-2(aiii)). There was a significant difference in the amplitude of control EPSPs that were potentiated or reduced by substance $\mathrm{P}(p<$ 0.05; Figures 2(ai)-2(aiii)), suggesting that the initial EPSP amplitude influenced the direction of the modulation. There was also a significant negative correlation between the initial EPSP amplitude and the magnitude of the EPSP potentiation $\left(r^{2}=0.2, n=22, p<0.05\right.$; Figure 2(b)) but no correlation between the initial EPSP amplitude and the magnitude of the EPSP reduction $\left(r^{2}=0.04, n=22, p>0.05\right.$; Figure 2(c)). A similar asymmetric relationship between the initial EPSP amplitude and the direction of the synaptic modulation has been reported previously [12, 21, 42-45], but the underlying mechanisms are unknown.

The modulation of the EPSP amplitude could reflect presynaptic or postsynaptic effects (changes in quantal content or quantal amplitude; [46]). Substance $P$ acts postsynaptically by potentiating the NMDA component of the EPSP (there is no evidence for AMPA-mediated effects; [47]). The role of NMDA receptor potentiation in the synaptic modulation was assessed using the EPSP half-width, which provides a measure of the NMDA component of the EPSP [48, 49]. Only connections in which the half-width could be clearly measured were used in the analysis. There was no significant difference in the control half-width at connections where the EPSP amplitude was potentiated or reduced by substance P 


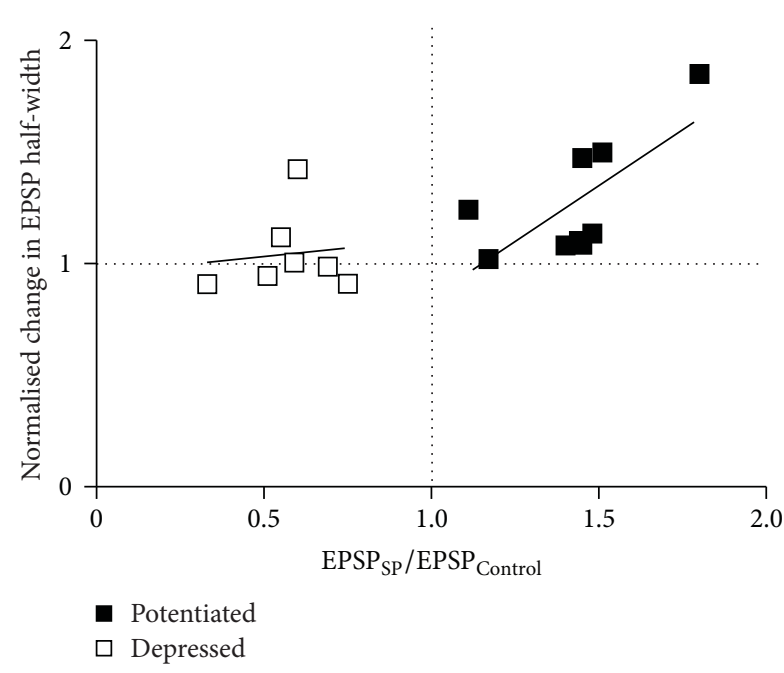

(a)

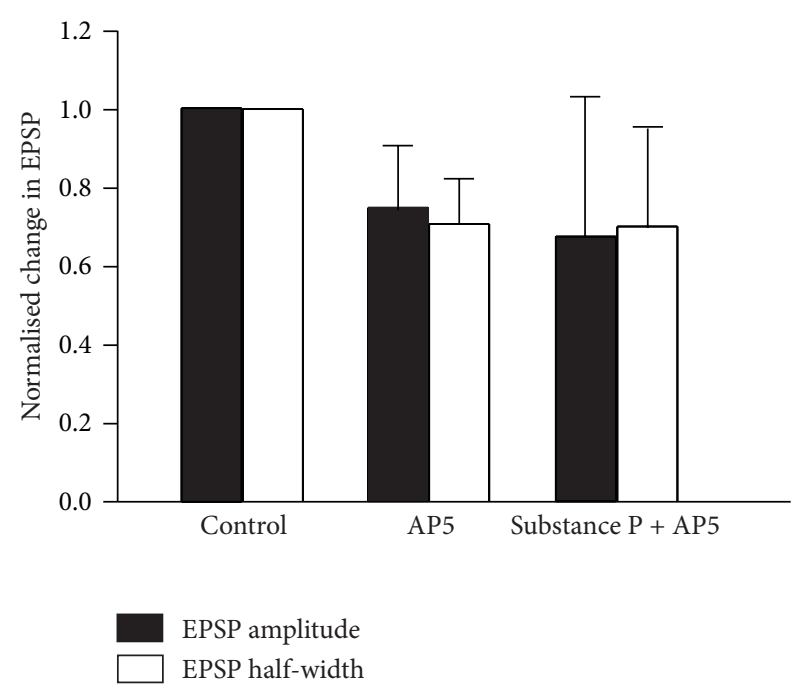

(b)

FIGURE 3: (a) Graph showing the relationship between the change in the EPSP amplitude (EPSP $\left.\mathrm{Subs}_{\mathrm{P}} / \mathrm{EPSP}_{\mathrm{Control}}\right)$ and the EPSP half-width at connections that were reduced or potentiated by substance P. (b) Bar graph showing the effects of blocking the NMDA component of the EPSP with AP5 $(100 \mu \mathrm{M})$ on the EPSP modulation by substance P. Effects are shown in comparison to the normalized control EPSP amplitude and half-width.

$(9.6 \pm 1.2 \mathrm{~ms}(n=9)$ compared to $9.9 \pm 1.3 \mathrm{~ms}(n=7)$, $p>0.05$; data not shown), suggesting against a difference in the initial NMDA component of the EPSP. However, the halfwidth was not significantly altered at connections that were reduced by substance $\mathrm{P}$ ( $97 \pm 7 \%$ of control; $p>0.05, n=7$; Figure 3(a)), but it was significantly increased at potentiated connections $(127 \pm 10 \% ; p<0.05, n=9$; Figure $3(\mathrm{a}))$. The potentiation also correlated with the magnitude of the halfwidth increase $\left(r^{2}=0.50, n=9, p<0.05\right.$; Figure 3(a)), and thus the change in the EPSP amplitude scaled with the magnitude of the postsynaptic effect. If the postsynaptic NMDAdependent effect influenced the EPSP potentiation, there should have been no potentiation when NMDA receptors were blocked. In AP5 $(100 \mu \mathrm{m})$ the EPSP amplitude and halfwidth were both reduced (data not shown). When substance $\mathrm{P}$ was applied in AP5, there was no significant effect overall on the EPSP amplitude or half-width $(n=8$; Figure $3(\mathrm{~b}))$. However, in individual connections, substance $\mathrm{P}$ could have no effect $(n=2)$, reduce $(n=5)$, or increase the EPSP amplitude ( $n=1$; data not shown), the variability suggesting the influence of other factors on the synaptic effects.

Presynaptic influences on the low frequency-evoked EPSP modulation were examined by estimating the available vesicle pool size and the release probability (see Figure 1(b) and Section 2 for details). There was no significant difference in the size of the estimated vesicle pool at connections that were potentiated or reduced by substance $\mathrm{P}(396 \pm 102(n=$ 7) and $334 \pm 67(n=11)$, resp.; $p>0.05$; Figure 4(a)), suggesting against a difference in the initial vesicle pool size. The role of the initial release probability was determined from the paired pulse (PP) ratio of connections before substance $P$ application. The initial PP ratio did not differ at connections that were potentiated or reduced $(1.22 \pm 0.1(n=22)$ compared to $1.01 \pm 0.1(n=22) ; p>0.05$; Figure 4(b)). However, there was a significant exponential relationship between the initial $\mathrm{PP}$ ratio and its change in substance $\mathrm{P}$ $\left(\mathrm{PP}_{\text {Subs } \mathrm{P}} / \mathrm{PP}_{\text {Control }} ; r^{2}=0.47, p<0.05\right.$; Figure $\left.4(\mathrm{c})\right)$. While there are few points in the high initial $\mathrm{PP}$ ratio range, this relationship suggested that over a certain range there was a state-dependent influence of the initial release probability on its subsequent change. This occurred up to a PP ratio of approximately 1.5 (equivalent to a release probability of $\sim 0.3$; see Figure 1(a)). Where the $\mathrm{PP}_{\text {Subs } \mathrm{P}} / \mathrm{PP}_{\text {Control }}$ ratio was increased (i.e., the release probability was reduced by substance P; Figure 4(c)), it was greater when the initial PP ratio was low (i.e., a high initial release probability). In some connections there was a decrease in the $\mathrm{PP}_{\text {Subs } \mathrm{P}} / \mathrm{PP}_{\text {Control }}$ ratio. This indicated an increase in release probability by substance P, which could have contributed to the EPSP potentiation.

The relationship between the EPSP amplitude and the $\mathrm{PP}$ ratio was examined by correlating the initial $\mathrm{PP}$ ratio to the change in the EPSP amplitude. When the EPSP amplitude was reduced $\left(\mathrm{EPSP}_{\text {Subs P }} / \mathrm{EPSP}_{\mathrm{Control}}<1\right)$, there was no significant correlation between the extent of the EPSP reduction and the initial PP ratio $\left(r^{2}=0.1, n=22, p>0.05\right.$; Figure $5(\mathrm{a}))$ or the change in the $\mathrm{PP}$ ratio by substance $\mathrm{P}$ $\left(\mathrm{PP}_{\text {Subs } \mathrm{P}} / \mathrm{PP}_{\text {Control }} ; r^{2}=0.13, n=22, p>0.05\right.$; Figure $5(\mathrm{~b}))$. At connections potentiated by substance $\mathrm{P}$ $\left(\mathrm{EPSP}_{\text {Subs } \mathrm{P}} / \mathrm{EPSP}_{\text {Control }}>1\right)$ there was again no significant correlation between the initial PP ratio and the change in the EPSP amplitude $\left(\mathrm{EPSP}_{\text {Subs } \mathrm{P}} / \mathrm{EPSP}_{\mathrm{Control}} ; r^{2}=0.23, n=\right.$ 10, $p>0.05$; Figure 5(a)). However, there was a significant negative correlation between the $\mathrm{PP}_{\text {Subs } \mathrm{P}} / \mathrm{PP}_{\text {Control }}$ and the $\mathrm{EPSP}_{\text {Subs P }} / \mathrm{EPSP}_{\text {Control }}\left(r^{2}=0.28, n=22, p<0.05\right.$; Figure 5(b)). A larger reduction of the release probability (i.e., $\mathrm{PP}_{\text {Subs } \mathrm{P}} / \mathrm{PP}_{\text {Control }}>1$ ) was thus associated with reduced 


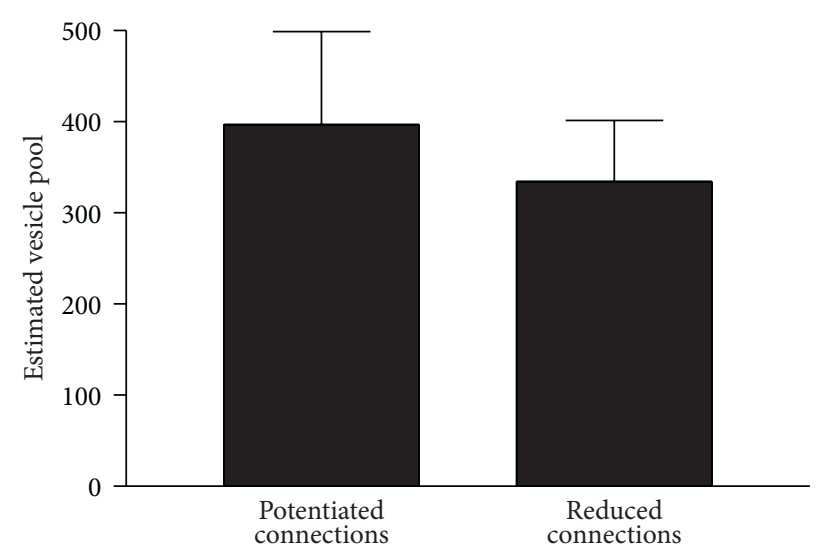

(a)

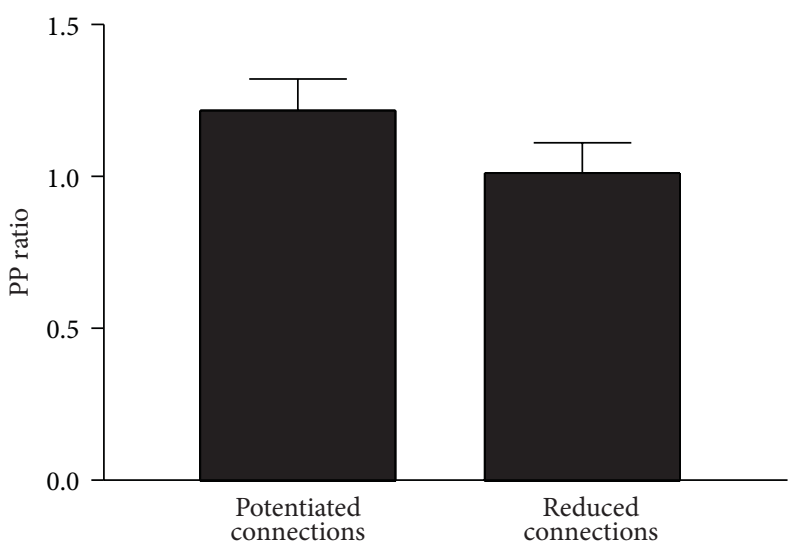

(b)

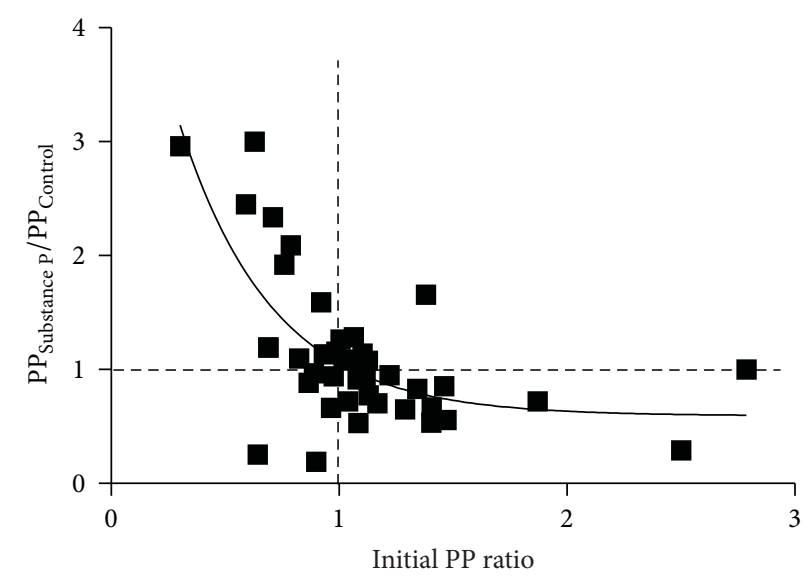

(c)

Figure 4: (a) Graph showing the size of the estimated available vesicle pool at connections that were potentiated or reduced by substance P. (b) Graph showing the PP ratio at connections that were potentiated or reduced by substance P. (c) Graph showing the relationship between the initial $\mathrm{PP}$ ratio and its change by substance $\mathrm{P}\left(\mathrm{PP}_{\text {Subs } \mathrm{P}} / \mathrm{PP}_{\text {Control }}\right)$.

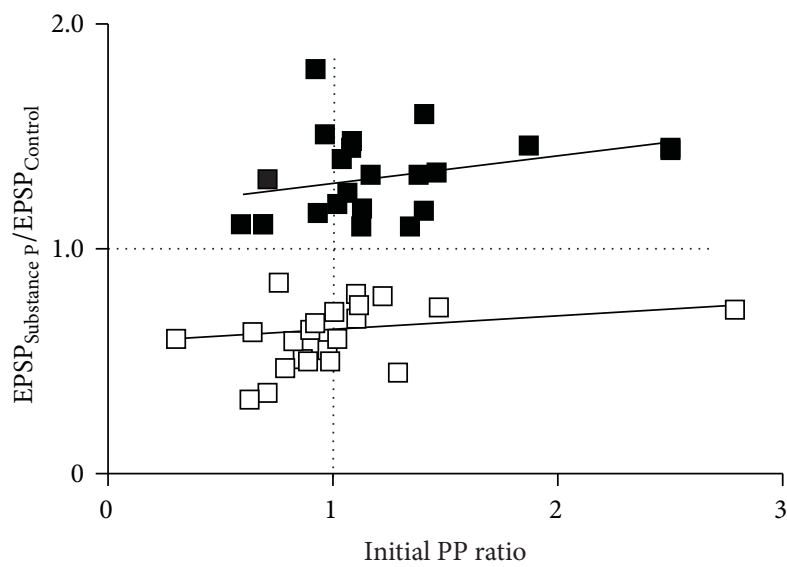

(a)

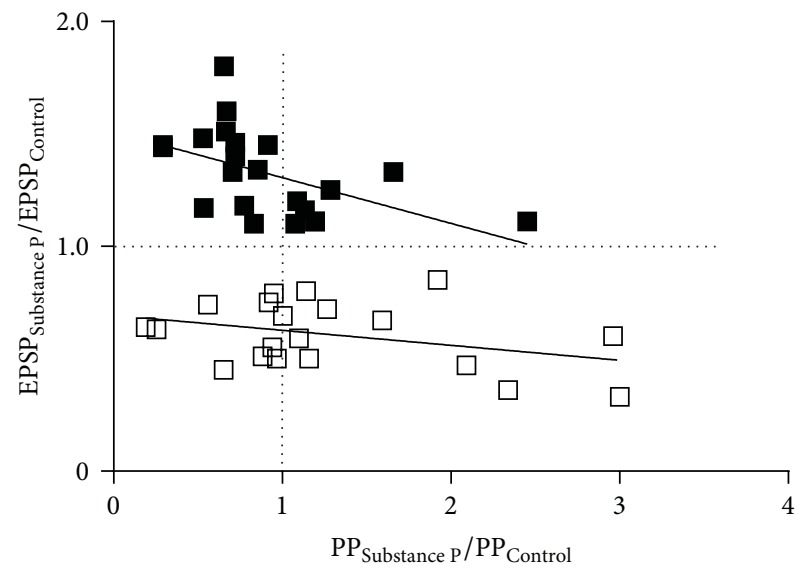

(b)

FIgURE 5: (a) The relationship between the initial PP ratio and the magnitude of the change in the EPSP amplitude by substance P $\left(\mathrm{EPSP}_{\text {Subs } \mathrm{P}} / \mathrm{EPSP}_{\mathrm{Control}}\right)$. Neither relationship was significant. (b) Graph showing the relationship between the change in the EPSP amplitude $\left(\mathrm{EPSP}_{\text {Subs } \mathrm{P}} / \mathrm{EPSP}_{\mathrm{Control}}\right)$ and the magnitude of the reduction in the $\mathrm{PP}$ ratio $\left(\mathrm{PP}_{\text {Subs } \mathrm{P}} / \mathrm{PP}_{\mathrm{Control}}\right)$. In this case, there was a significant negative correlation at potentiated connections. 
potentiation. This may reflect a subtractive effect of the reduced presynaptic release probability on the postsynaptic potentiation of NMDA responses.

3.2. Substance P Effects during Spike Trains. Substance P can reduce depression or increase facilitation over spike trains [28]. This can occur with an increase or decrease of the initial EPSP amplitude to give metaplastic or release probabilitydependent effects, respectively. Reduced depression or facilitation from an increased EPSP amplitude is defined as metaplasticity, while reduced depression form a smaller initial EPSP or increased depression from a larger initial EPSP is defined as release probability-dependent plasticity $\left(\mathrm{RP}_{\mathrm{Fac}}\right.$ and $\mathrm{RP}_{\text {Dep }}$, respectively; see Figure 1(c)). Metaplasticity occurred in 19 of 40 connections ( $48 \%$, which is comparable to that in a smaller sample size, 58\%; [25]), $\mathrm{RP}_{\text {Dep }}$ occurred in 7 connections, and $\mathrm{RP}_{\mathrm{Fac}}$ occurred in 10 connections. In a small number of connections, substance $\mathrm{P}$ increased depression from a reduced initial EPSP amplitude $(n=4)$. This latter effect differs from that expected of a release probabilitydependent plasticity mechanism and could be considered metaplastic depression: because of the small sample size these connections were not analysed further.

Of the 19 connections that showed metaplasticity, 10 had a Train ${ }_{2-5}$ response after substance $\mathrm{P}$ that fell below the $110 \%$ cut-off limit (see Section 2), so only the 9 relatively strongly altered connections were analysed here. There was no significant difference in the control initial EPSP amplitude in the spike train $(p>0.05$; Figure $6(\mathrm{a}))$ or the PP ratio $(p>0.05$; Figure 6(b)) at connections where metaplasticity or release probability-dependent plasticity occurred. There was also no significant correlation between the initial EPSP amplitude and the activity-dependent plasticity in control $\left(\operatorname{Train}_{2-5} r^{2}=\right.$ $0.09 ; p>0.05$; Figure 6(ci)) or after substance P application $\left(\operatorname{Train}_{2-5}\right.$ Subs P $r^{2}=0.12, p>0.05$; Figure 6(cii)). The lack of correlation between the initial EPSP and the plasticity over spike trains presumably reflects the influence of multiple interacting parameters on synaptic properties (see [50,51]).

The lack of a difference in the initial PP ratio suggested that the initial release probability did not determine the type of plasticity evoked. However, when the control PP ratio was related to the $\operatorname{Train}_{2-5}$ plasticity after substance $\mathrm{P}$ application $\left(\operatorname{Train}_{\text {Subs } \mathrm{P}} / \operatorname{Train}_{\text {Control }}\right)$, there was a significant negative correlation between the initial PP ratio and the substance Pinduced change in Train ${ }_{2-5}$ plasticity at connections where release probability-dependent plasticity $\left(\mathrm{RP}_{\text {Dep }}\right.$ and $\left.\mathrm{RP}_{\mathrm{Fac}}\right)$ or metaplasticity occurred $\left(r^{2}=0.47\right.$ and 0.42 , resp.; $p<$ 0.05 ; see Figures $6(\mathrm{di})$ and $6(\mathrm{dii}))$. The reduced depression during spike trains, either metaplastic or release probabilitydependent, was thus greater when the initial PP ratio was low (release probability was high).

The number of vesicles in glutamatergic terminals is increased by substance P [25]. Given that there must be a physical limit on the number of vesicles at typical central synaptic terminals [52], a large initial vesicle pool could provide a state-dependent influence on the activity-dependent plasticity by limiting the potential for any increase. Support for this was obtained from estimates of the number of available vesicles before substance $\mathrm{P}$ application. This was significantly smaller at connections that showed metaplasticity $(n=4)$ than at those that exhibited release probabilitydependent plasticity $(n=9 ; p<0.05$; Figure $7(\mathrm{a}))$.

While the quantal model assumes the vesicle pool and release probability are independent, they can be related. Larger vesicle pools are typically associated with higher release probabilities ([53-56]; but see [57]). The relationship between the vesicle pool size and the release probability was examined by relating the estimated number of available vesicles to the PP ratio. This relationship was fit by a single exponential association $\left(r^{2}=0.83, p<0.05, n=16\right.$; Figure $7(b)$ ), and thus over a certain range smaller estimated vesicle pools were associated with higher release probabilities (a similar effect occurs at the crayfish neuromuscular junction; [57]). This suggests a link between the smaller vesicle pools and high initial release probabilities that are needed to evoke metaplasticity.

3.3. Effects of Manipulating the Release Probability. While the analysis identified effects associated with the plasticity of EIN-evoked EPSPs, the analysis is correlational. An obvious approach is to alter the initial synaptic properties to put the synapses into functional states that should promote or inhibit the different forms of plasticity. However, this is complicated by the involvement of multiple presynaptic and postsynaptic effects that cannot be targeted specifically, either because their mechanisms are unknown or because specific tools are lacking (see [58]). The release probability was the obvious target as it had a state-dependent influence on both forms of plasticity and it can be manipulated (albeit not specifically). Attempts to change the state of the synapse were made here by reducing the release probability using high $\mathrm{Mg}^{2+}$ Ringer.

High $\mathrm{Mg}^{2+}$ Ringer nonsignificantly reduced the initial EPSP amplitude $(n=20, p>0.05)$ but significantly increased the PP ratio $(n=18, p<0.05)$; (Figure $8(\mathrm{a})$ ). The latter effect was consistent with a $\mathrm{Mg}^{2+}$-dependent reduction of the release probability. This should promote potentiation of the low frequency-evoked EPSP amplitude by substance P by reducing the potential subtractive effect of the reduction in release probability. However, in high $\mathrm{Mg}^{2+}, 13$ connections were potentiated (from $1.1 \pm 0.3 \mathrm{mV}$ to $1.5 \pm 0.4 \mathrm{mV}, p<0.05$ ), and 7 connections were reduced (from $1.4 \pm 0.3 \mathrm{mV}$ to $0.9 \pm$ $0.3 \mathrm{mV}, p<0.05)$. The relative proportion of effects in high $\mathrm{Mg}^{2+}$ Ringer did not differ from that in normal Ringer $(p>$ 0.5 , Chi square), and thus reducing the release probability did not direct the plasticity of the synapses in the predicted way. A potential complication here is a change in the $\mathrm{Mg}^{2+}$ block of NMDA receptors [59, 60], which could reduce the postsynaptic potentiation and oppose the effects of the reduction in release probability on the potentiation. This was supported by analyses of the EPSP half width: in high $\mathrm{Mg}^{2+}$ Ringer there was no significant change in the EPSP half-width at connections that were either reduced or potentiated $(p<$ 0.05 , Figure $8(\mathrm{c})$ ), suggesting a reduced postsynaptic effect.

While the opposing influences of high $\mathrm{Mg}^{2+}$ on the release probability and NMDA potentiation complicated 


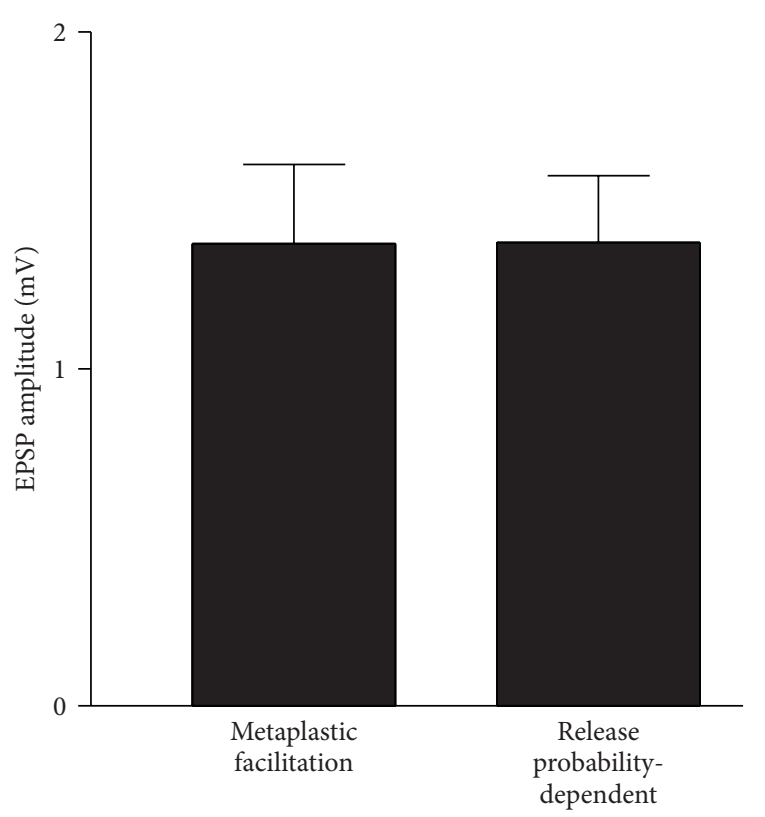

(a)

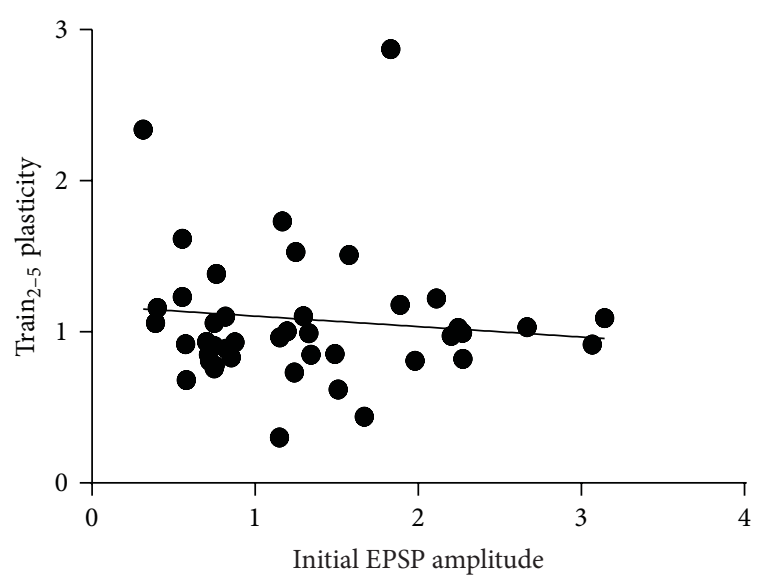

(ci)

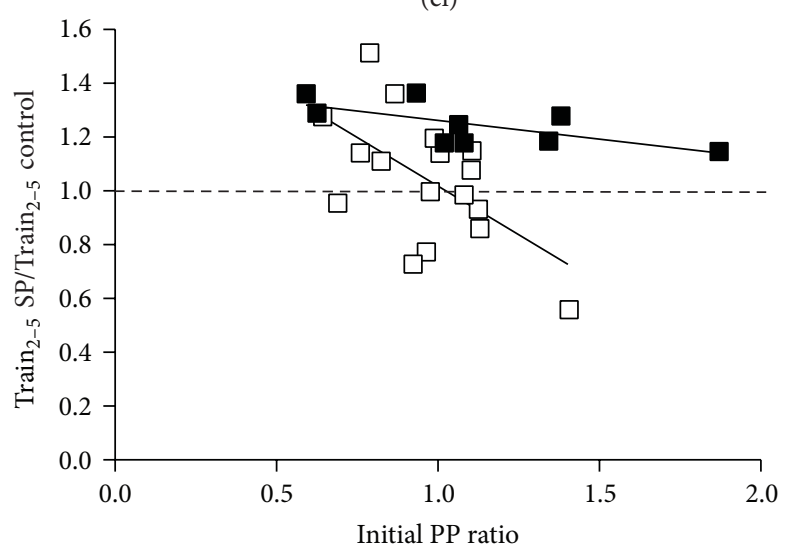

(di)

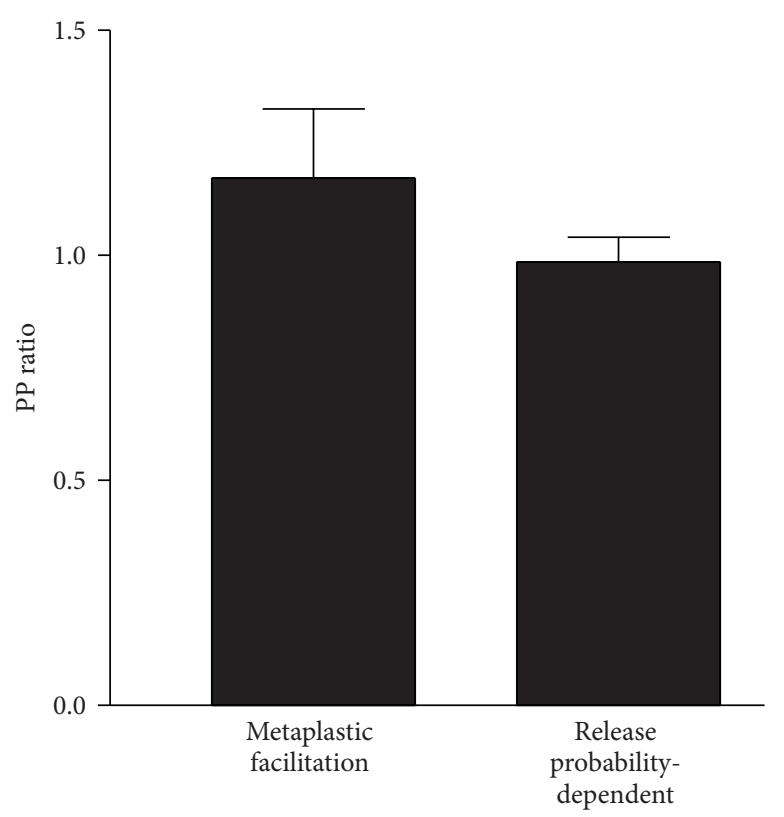

(b)

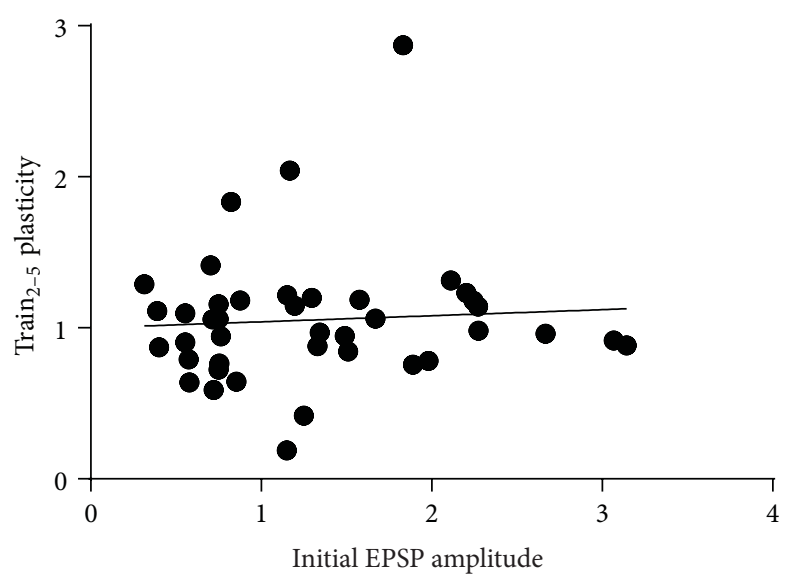

(cii)

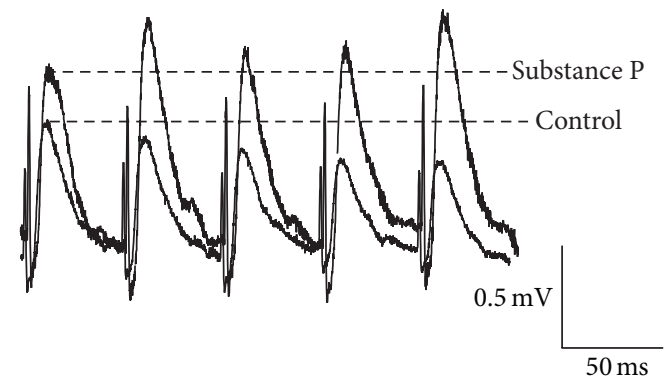

(dii)

FIGURE 6: (a) Graph showing the lack of a significant difference in the EPSP amplitude at connections where metaplasticity or release probability-dependent plasticity occurred. (b) Graph showing the PP ratio at connections where different forms of activity-dependent plasticity occurred. (ci) Graph showing the relationship between the initial EPSP amplitude and the Train ${ }_{2-5}$ plasticity in control and in substance P (cii). (di) Graph showing changes in the PP ratio for the different forms of plasticity. (dii) Traces showing the changes in EPSP amplitude over spike trains. 


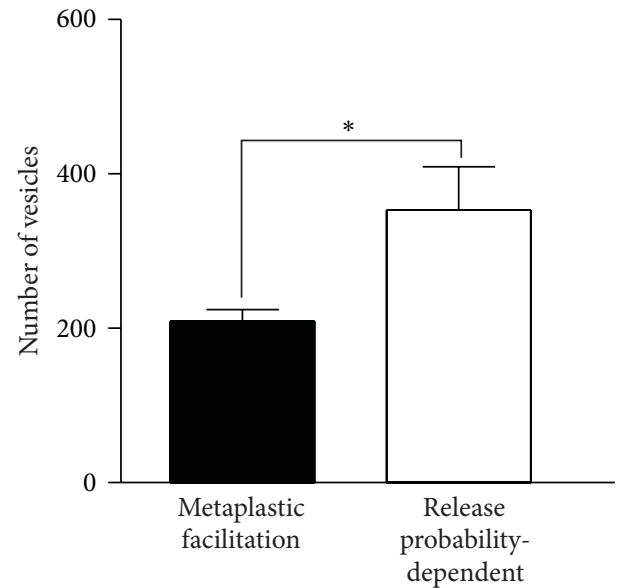

(a)

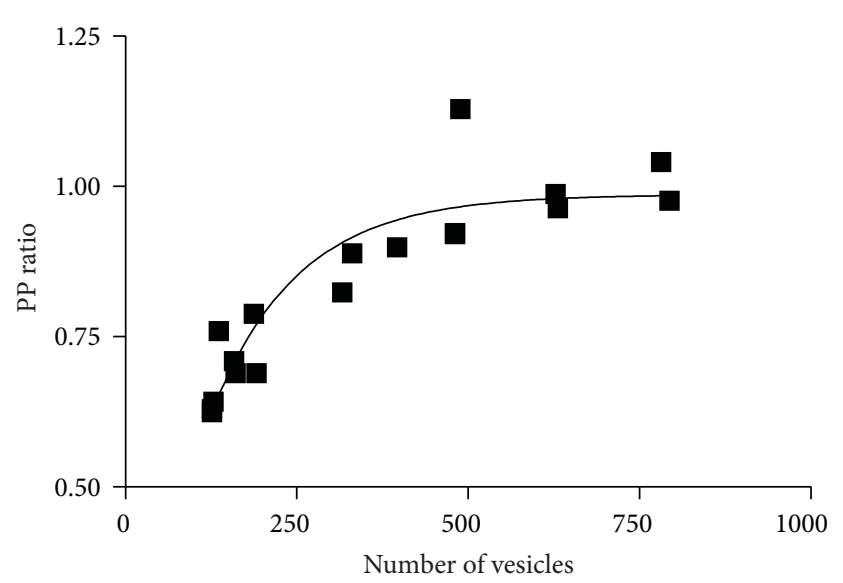

(b)

Figure 7: (a) There was a significant difference in the available vesicle pool at connections where metaplasticity or release probabilitydependent plasticity occurred. (b) Graph showing the relationship between the number of vesicles and the PP ratio. The data is fit with a single exponential association and suggests that the influence of vesicle numbers on the PP ratio plateaued at approximately 1.0.

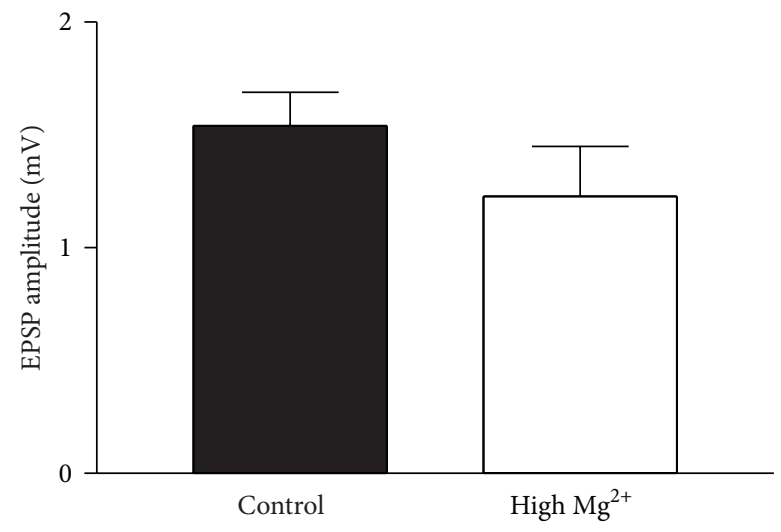

(a)

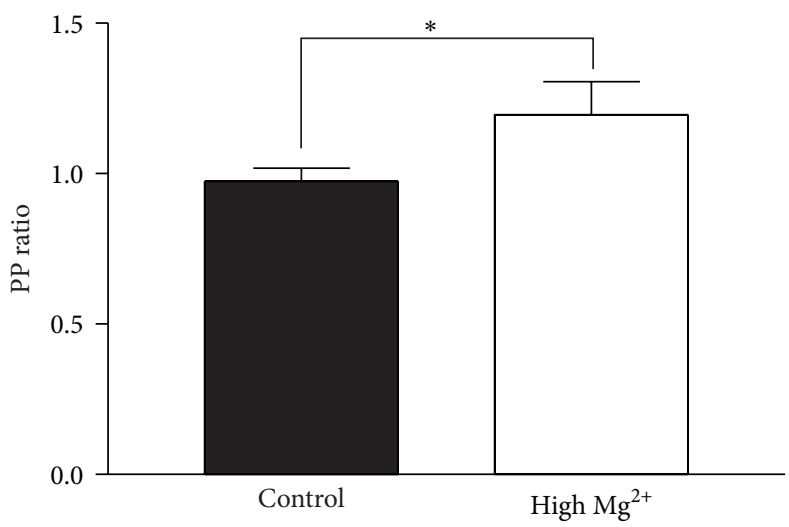

(b)

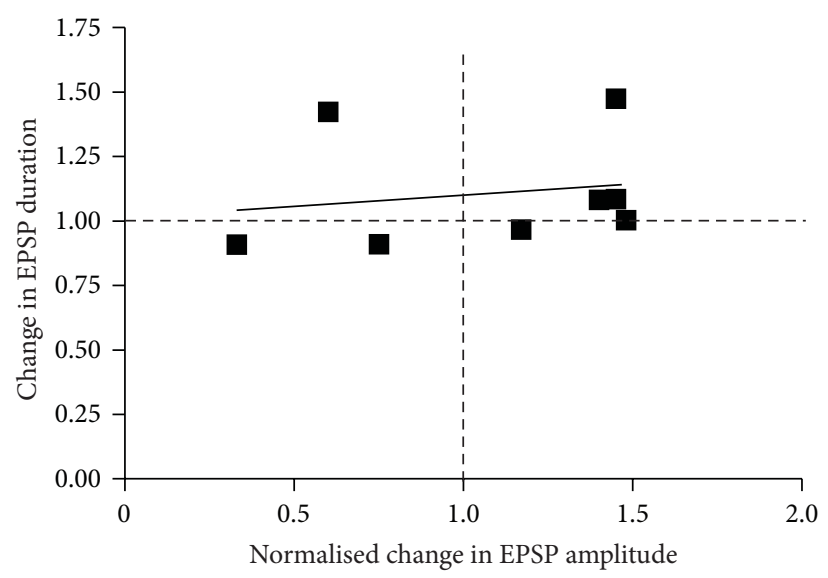

(c)

Figure 8: The effects of high $\mathrm{Mg}^{2+}$ Ringer on substance P-evoked synaptic modulation. Graphs show the lack of a significant effect of high $\mathrm{Mg}^{2+}$ on the EPSP amplitude (a) but a significant increase in the PP ratio (b), indicative of a reduction in release probability. (c) Graph showing the EPSP half-width at connections where the low frequency-evoked EPSP amplitude was potentiated or depressed by substance P. 
attempts to direct the modulation of the initial EPSP, metaplasticity is not dependent on the postsynaptic NMDA effect [28], making this less of a confounding factor. The reduction in release probability in high $\mathrm{Mg}^{2+}$ Ringer (Figure 8(b)) should shift the synapse away from the region where metaplasticity would be promoted (Figure 6(di)). In high $\mathrm{Mg}^{2+}$ Ringer metaplasticity that exceeded the criteria used above did not occur in any connection $(n=16)$, although other effects occurred, including release probability-dependent depression $(n=6)$, release probability-dependent facilitation $(n=6)$, or increased depression from a lower initial EPSP amplitude $(n=2)$. Taking connections where changes below threshold occurred, metaplasticity still occurred in a significantly lower proportion of connections in high $\mathrm{Mg}^{2+}$ Ringer $(n=2$ of 16$)$ than in control Ringer $(n=19$ of 40 ; $p<0.05$ Chi square), consistent with metaplasticity being associated with relatively high initial release probabilities.

\section{Discussion}

In addition to characterizing the changes associated with synaptic and other forms of plasticity, given that plasticity is variable, there is also a need to focus on the conditions that influence its expression (see [61]). This study has extended the analysis of excitatory interneuron (EIN) synaptic properties $[23,62]$ to focus on how the marked variability of this connections influenced synaptic plasticity. The results suggest that variability of the synapse can influence the type and magnitude of synaptic modulation.

The potentiation of low frequency-evoked EPSPs reflected an antagonistic interaction between the postsynaptic NMDA-dependent potentiation of the EPSP and a statedependent subtractive reduction of the release probability. Over spike trains, facilitation was the typical effect of substance P. This could occur with a reduction or increase in the initial EPSP amplitude (release probability-dependent plasticity and metaplasticity, resp.). State-dependent influences on whether metaplasticity rather than release probability-dependent plasticity was evoked were the initial release probability and the size of the available vesicle pool.

The changes in single EPSPs showed effects similar to soft bound plasticity considered in memory systems, where stronger synapses (larger EPSPs) potentiate less than weaker synapses, but a reduction of the EPSP is independent of the initial EPSP amplitude [12]. Bounds on potentiation may reflect resource addition (e.g., available vesicles), and as these are finite they place a limit on further potentiation. This may reflect a homeostatic mechanism that limits synapses to a range of values and so prevents potentiation above a certain level. However, as a reduction is subtractive, it could in principle occur from any level ultimately to zero. Activitydependent changes, which determine synaptic strength over spike trains, showed no influence of the initial EPSP amplitude on the direction of the plasticity. The different influences of the initial EPSP amplitude on low frequency and activity-dependent synaptic plasticity suggest that making links between synaptic plasticity or modulation and the initial synaptic strength will depend on how the initial synaptic strength is defined (i.e., single inputs or effects over spike trains).

The changes in low frequency and activity-dependent effects over spike trains showed little correlation (see also [23]). While a state-dependent influence of the release probability was a common link, it had opposite influences: a high release probability favoured metaplasticity and a low release probability favoured potentiation of the initial EPSP amplitude. The lack of correlation between the initial and activitydependent effects probably reflects the multiple factors that influence synaptic properties (e.g., [51]), with the net effect depending on the relative influence of different parameters. If activity-dependent synaptic depression was reduced by lowering the release probability, then the initial EPSP amplitude should also be reduced. However, with an associated postsynaptic potentiation of NMDA responses or an increase in vesicle numbers, a reduction of release probability can lead to reduced depression from an unchanged or increased initial EPSP. This offers greater flexibility than a single or fixed combined mechanism: release probability-dependent plasticity alone would redistribute effects over the spike train (depression occurring from larger initial EPSPs and facilitation from smaller EPSPs) and limit the potential for changes in overall synaptic strength, while synaptic scaling removes the potential computational advantages of activity-dependent plasticity over spike trains [63]. While low frequency and activitydependent effects were separated here for analytical convenience, how they actually interact now requires analysis.

There was an interaction between the available vesicle pool and release probability, both of which influenced the metaplasticity. Larger vesicle pools are typically associated with larger release probabilities [53-56]. The opposite interaction occurred here where there was an inverse relationship between the release probability and the estimated vesicle pool size (see also [57]). The mechanisms underlying this interaction are unknown, but they could relate to increased vesicle competition for calcium or greater calcium buffering with high vesicle densities. The effect plateaued at a PP ratio of approximately 1, equivalent to a release probability of $\sim 0.5$. Matching a high release probability with a smaller vesicle pool offers the potential to increase vesicle numbers when there was a larger relative reduction in release probability. This could increase the quantal content despite a reduction in release probability allowing metaplasticity rather than the expected release probability-dependent facilitation [25]. This was supported by release probability-dependent facilitation at connections where the initial vesicle pool was larger.

While the effects selected for analysis here can account for some of the variability of plasticity, they clearly cannot account for it all (e.g., metaplasticity could fail at connections with small depressing EPSPs that suggest high initial release probabilities and small vesicle pools which offer the ideal initial conditions for inducing metaplasticity). This may reflect differences in induction mechanisms (e.g., activation of second messenger pathways; [64]) needed to trigger effects [47], random effects on synaptic processes [10], or as yet unidentified, state-dependent influences.

In addition to the selective analysis of low frequency and spike train effects, an additional weakness is that it is largely 
correlative. This reflects the general difficulties of examining and altering synaptic properties. Attempts at directing plasticity by altering the release probability in high $\mathrm{Mg}^{2+}$ Ringer were not ideal as NMDA properties would also be affected. Altering Ringer $\mathrm{Ca}^{2+}$ levels was not an option as it would affect many other calcium-dependent presynaptic $[40,65]$ and postsynaptic processes (changes in NMDA receptor conductance and desensitization; [66]). However, for the metaplasticity (where NMDA-dependent effects do not appear to be necessary; [28]), there was support for the state-dependent influence of the initial release probability.

4.1. Functional Implications. Variability is necessary to any adaptive system $[67,68]$. EIN cellular and synaptic properties vary markedly $[23,34,69]$. Assuming that this is not random variation in EIN properties, this suggests the presence of functional subpopulations [23]. As the EINs provide the excitatory drive to the network [24], the activation of different subpopulations should alter the motor output. This could potentially account for the variability of fictive locomotion (see $[47,70]$ ). While it has seldom been discussed (see [71]), the variable output evoked under what seems to be identical conditions is arguably a defining feature of fictive locomotor activity. This variability could be explained by the random activation of different populations of EINs by bath applied glutamate agonists.

The network relevance of variable cellular and synaptic properties is uncertain [11] and remains to be determined in spinal cord locomotor networks. The network effects of substance $P$ are also variable and state-dependent: the modulation of the frequency and regularity of network activity both vary markedly [47], and both depend on their initial values [47], although it is not known how this relates to the statedependent effects on single synapses suggested here. Pérez et al. [72] show a disparity in substance P effects as their increase in burst frequency was less than a previous analysis [47]. This may reflect the problems of getting stable fictive activity, but the time that preparations were left to reach stability ( $4 \mathrm{~h}$ in [47]) matches the time needed for stability in [72]. However, the large effects Pérez et al. compare to only occur from low initial frequencies [47]; the disparity largely disappears when similar starting frequencies are considered (e.g., a starting frequency of $1.5 \mathrm{~Hz}$ gives $\sim 20 \%$ increase in [72] compared to $\sim 40 \%$ in [47]). Nevertheless, arguably the most constant feature of fictive activity is its variability, which obviously complicates studies of network mechanisms. Ideally, the initial state of synapses would be altered to see if network modulation could be directed, but this would be difficult due to the multiple cellular and synaptic effects involved in network function and plasticity.

Substance P can modulate variability [62], an effect also seen here. In the sample size examined, in control, $47 \%$ of connections depressed, $37 \%$ were facilitated, and $16 \%$ were unchanged over $\operatorname{Train}_{2-5}$ (this approximately matched the proportions in a much larger sample where $46 \%$ depressed, $27 \%$ were facilitated, and $12 \%$ were unchanged; [23]). After substance $\mathrm{P}$ application 29 of 40 connections were facilitated
(72.4\%; this is either release probability-dependent or metaplastic). Substance $\mathrm{P}$ thus reduced the variability of activitydependent plasticity. The effect that this has on the network can be considered as the relative excitatory drive to motor neurons calculated as

$$
\begin{aligned}
& \text { EPSP }_{\text {Init }} \times \operatorname{Train}_{2-5} \text { Plasticity } \\
& \quad \times \text { Proportion of connections. }
\end{aligned}
$$

In control, $D=0.43, F=0.66$, and $U=0.32$, giving a total of 1.41 in control and 1.34 after substance P. This argues against the assumption that substance $\mathrm{P}$ alters the network output by increasing network excitability by increasing glutamatergic drive [47] and instead suggests a change in EIN synaptic properties that preserve their overall synaptic effect. However, substance P also increases EIN excitability and reduces spike variability $[27,62]$, effects that could lead to enhanced activation and synchronization of the EIN pool.

\section{Conclusions}

This analysis adds to the evidence for significant synaptic variability in spinal locomotor networks [73-79]. The EINs have been referred to as a "relatively homogeneous" population [80], a claim that ignored the known variability of these cells and their synaptic connections $[23,34,62,69]$. It has also been stated that there has been no analysis of different functional classes of the EINs [81], a claim that ignores the analysis of functional subdivisions within this interneuron population [23]. This variability can be modulated [62], and, as shown here, the variability can influence the potential for synaptic plasticity. In addition to determining the functional roles of different cell classes in spinal cord (and other) networks, the variability suggests that we will have to consider finer subdivisions in cell populations than suggested by traditional anatomical, molecular, or physiological markers. In lamprey and other systems, network synaptic interactions are routinely examined from spontaneous or locomotor-related PSPs or inputs evoked by extracellular stimulation. While these approaches have the advantage of speed, they essentially average across an unknown number of unknown inputs and ignore the heterogeneity of cellular and synaptic populations. Given the increasing awareness of the importance of variable parameters in network function (see [82]), the limitations of these approaches to understanding network function and plasticity need to be acknowledged and addressed.

\section{Conflict of Interests}

The author declares that there is no conflict of interests regarding the publication of this paper.

\section{Acknowledgments}

The early stage of this work was supported by grants from the UK Biotechnology and Biological Sciences Research Council and the Royal Society. 


\section{References}

[1] I. Aradi and I. Soltesz, "Modulation of network behaviour by changes in variance in interneuronal properties," Journal of Physiology, vol. 538, no. 1, pp. 227-251, 2002.

[2] C. Földy, I. Aradi, A. Howard, and I. Soltesz, "Diversity beyond variance: modulation of firing rates and network coherence by GABAergic subpopulations," European Journal of Neuroscience, vol. 19, no. 1, pp. 119-130, 2004.

[3] K. M. Franks, C. F. Stevens, and T. J. Sejnowski, "Independent sources of quantal variability at single glutamatergic synapses," Journal of Neuroscience, vol. 23, no. 8, pp. 3186-3195, 2003.

[4] J.-M. Goaillard, A. L. Taylor, D. J. Schulz, and E. Marder, "Functional consequences of animal-to-animal variation in circuit parameters," Nature Neuroscience, vol. 12, no. 11, pp. 1424-1430, 2009.

[5] E. Hanse and B. Gustafsson, "Quantal variability at glutamatergic synapses in area CAl of the rat neonatal hippocampus," Journal of Physiology, vol. 531, no. 2, pp. 467-480, 2001.

[6] K. M. Harris and P. Sultan, "Variation in the number, location and size of synaptic vesicles provides an anatomical basis for the nonuniform probability of release at hippocampal CA1 synapses," Neuropharmacology, vol. 34, no. 11, pp. 1387-1395, 1995.

[7] E. Marder and J.-M. Goaillard, "Variability, compensation and homeostasis in neuron and network function," Nature Reviews Neuroscience, vol. 7, no. 7, pp. 563-574, 2006.

[8] P. Parra, A. I. Gulyás, and R. Miles, "How many subtypes of inhibitory cells in the hippocampus?" Neuron, vol. 20, no. 5, pp. 983-993, 1998.

[9] A. A. Prinz, D. Bucher, and E. Marder, "Similar network activity from disparate circuit parameters," Nature Neuroscience, vol. 7, no. 12, pp. 1345-1352, 2004.

[10] C. Ribrault, K. Sekimoto, and A. Triller, "From the stochasticity of molecular processes to the variability of synaptic transmission," Nature Reviews Neuroscience, vol. 12, no. 7, pp. 375-387, 2011.

[11] I. Soltesz, Diversity in the Neuronal Machine, Oxford University Press, 2006.

[12] D. Debanne, B. H. Gähwiler, and S. M. Thompson, "Heterogeneity of synaptic plasticity at unitary CA3-CA1 and CA3-CA3 connections in rat hippocampal slice cultures," The Journal of Neuroscience, vol. 19, no. 24, pp. 10664-10671, 1999.

[13] F. A. Edwards, "LTP-a structural model to explain the inconsistencies," Trends in Neurosciences, vol. 18, no. 6, pp. 250-255, 1995.

[14] D. L. Glanzman, "The cellular basis of classical conditioning in Aplysia californica-It's less simple than you think," Trends in Neurosciences, vol. 18, no. 1, pp. 30-36, 1995.

[15] J. Lisman, J. W. Lichtman, and J. R. Sanes, "LTP: perils and progress," Nature Reviews Neuroscience, vol. 4, no. 11, pp. 926929, 2003.

[16] E. A. Marcus and T. J. Carew, "Developmental emergence of different forms of neuromodulation in Aplysia sensory neurons," Proceedings of the National Academy of Sciences of the United States of America, vol. 95, no. 8, pp. 4726-4731, 1998.

[17] C. C. H. Petersen, R. C. Malenka, R. A. Nicoll, and J. J. Hopfield, "All-or-none potentiation at CA3-CA1 synapses," Proceedings of the National Academy of Sciences of the United States of America, vol. 95, no. 8, pp. 4732-4737, 1998.

[18] C. Rosenmund, J. D. Clements, and G. L. Westbrook, "Nonuniform probability of glutamate release at a hippocampal synapse," Science, vol. 262, no. 5134, pp. 754-757, 1993.
[19] G. Turrigiano, "Homeostatic signaling: the positive side of negative feedback," Current Opinion in Neurobiology, vol. 17, no. 3, pp. 318-324, 2007.

[20] L. L. Voronin and E. Cherubini, “'Deaf, mute and whispering' silent synapses: their role in synaptic plasticity," The Journal of Physiology, vol. 557, no. 1, pp. 3-12, 2004.

[21] X.-D. Yang and D. S. Faber, "Initial synaptic efficacy influences induction and expression of long-term changes in transmission," Proceedings of the National Academy of Sciences of the United States of America, vol. 88, no. 10, pp. 4299-4303, 1991.

[22] S. Zhao, A. F. Sheibanie, M. Oh, P. Rabbah, and F. Nadim, "Peptide neuromodulation of synaptic dynamics in an oscillatory network," Journal of Neuroscience, vol. 31, no. 39, pp. 1399114004, 2011.

[23] D. Parker, "Variable properties in a single class of excitatory spinal synapse," The Journal of Neuroscience, vol. 23, no. 8, pp. 3154-3163, 2003.

[24] J. T. Buchanan, "Contributions of identifiable neurons and neuron classes to lamprey vertebrate neurobiology," Progress in Neurobiology, vol. 63, no. 4, pp. 441-466, 2001.

[25] S. Bevan and D. Parker, "Metaplastic facilitation and ultrastructural changes in synaptic properties are associated with long-term modulation of the lamprey locomotor network," The Journal of Neuroscience, vol. 24, no. 42, pp. 9458-9468, 2004.

[26] S. Bevan, V. Vakharia, and D. Parker, "Changes in gene expression and integrin-mediated structural changes are associated with long-term plasticity of a spinal cord locomotor network," Neuroscience, vol. 152, no. 1, pp. 160-168, 2008.

[27] D. Parker and S. Grillner, "Cellular and synaptic modulation underlying substance P-mediated plasticity of the lamprey locomotor network," Journal of Neuroscience, vol. 18, no. 19, pp. 8095-8110, 1998.

[28] D. Parker and S. Grillner, "Activity-dependent metaplasticity of inhibitory and excitatory synaptic transmission in the lamprey spinal cord locomotor network," The Journal of Neuroscience, vol. 19, no. 5, pp. 1647-1656, 1999.

[29] E. Svensson, S. Grillner, and D. Parker, "Gating and braking of short- and long-term modulatory effects by interactions between colocalized neuromodulators," Journal of Neuroscience, vol. 21, no. 16, pp. 5984-5992, 2001.

[30] E. Svensson, S. Grillner, and D. Parker, "Synaptically evoked membrane potential oscillations induced by substance $\mathrm{P}$ in lamprey motor neurons," Journal of Neurophysiology, vol. 87, no. 1, pp. 113-121, 2002.

[31] M. J. Friedlander, R. J. Sayer, and S. J. Redmann, "Evaluation of long-term potentiation of small compound and unitary EPSPs at the hippocampal CA3-CA1 synapse," Journal of Neuroscience, vol. 10, no. 3, pp. 814-825, 1990.

[32] M. S. Berry and V. W. Pentreath, "Criteria for distinguishing between monosynaptic and polysynaptic transmission," Brain Research, vol. 105, no. 1, pp. 1-20, 1976.

[33] J. T. Buchanan and S. Kasicki, "Activities of spinal neurons during brain stem-dependent fictive swimming in lamprey," Journal of Neurophysiology, vol. 73, no. 1, pp. 80-87, 1995.

[34] J. T. Buchanan, S. Grillner, S. Cullheim, and M. Risling, "Identification of excitatory interneurons contributing to generation of locomotion in lamprey: structure, pharmacology, and function," Journal of Neurophysiology, vol. 62, no. 1, pp. 59-69, 1989.

[35] M. McLachlan and A. R. Martin, "Non-linear summation of end-plate potentials in the frog and mouse," Journal of Physiology, vol. 311, pp. 307-324, 1981. 
[36] A. Arai and G. Lynch, "AMPA receptor desensitization modulates synaptic responses induced by repetitive afferent stimulation in hippocampal slices," Brain Research, vol. 799, no. 2, pp. 235-242, 1998.

[37] G. Liu, "Presynaptic control of quantal size: kinetic mechanisms and implications for synaptic transmission and plasticity," Current Opinion in Neurobiology, vol. 13, no. 3, pp. 324-331, 2003.

[38] V. Scheuss, R. Schneggenburger, and E. Neher, "Separation of presynaptic and postsynaptic contributions to depression by covariance analysis of successive EPSCs at the calyx of held synapse," The Journal of Neuroscience, vol. 22, no. 3, pp. 728-739, 2002.

[39] R. Tureček and L. O. Trussell, "Control of synaptic depression by glutamate transporters," The Journal of Neuroscience, vol. 20, no. 5, pp. 2054-2063, 2000.

[40] C. Wang and R. S. Zucker, "Regulation of synaptic vesicle recycling by calcium and serotonin," Neuron, vol. 21, no. 1, pp. 155-167, 1998.

[41] D. Parker, "Activity and calcium-dependent mechanisms maintain reliable interneuron synaptic transmission in a rhythmic neural network," Journal of Neuroscience, vol. 20, no. 5, pp. 1754$1766,2000$.

[42] G.-Q. Bi and M.-M. Poo, "Synaptic modifications in cultured hippocampal neurons: dependence on spike timing, synaptic strength, and postsynaptic cell type," Journal of Neuroscience, vol. 18, no. 24, pp. 10464-10472, 1998.

[43] M. Ghirardi, O. Braha, B. Hochner, P. G. Montarolo, E. R. Kandel, and N. Dale, "Roles of PKA and PKC in facilitation of evoked and spontaneous transmitter release at depressed and nondepressed synapses in aplysia sensory neurons," Neuron, vol. 9, no. 3, pp. 479-489, 1992.

[44] M. C. W. Van Rossum and G. G. Turrigiano, "Correlation based learning from spike timing dependent plasticity," Neurocomputing, vol. 38-40, pp. 409-415, 2001.

[45] M. C. W. van Rossum, M. Shippi, and A. B. Barrett, "Softbound synaptic plasticity increases storage capacity," PLoS Computational Biology, vol. 8, no. 12, Article ID e1002836, 2012.

[46] A. M. Thomson, "Molecular frequency filters at central synapses," Progress in Neurobiology, vol. 62, no. 2, pp. 159-196, 2000.

[47] D. Parker, W. Zhang, and S. Grillner, "Substance P modulates NMDA responses and causes long-term protein synthesisdependent modulation of the lamprey locomotor network," The Journal of Neuroscience, vol. 18, no. 12, pp. 4800-4813, 1998.

[48] N. Dale and A. Roberts, "Excitatory amino acid receptors in Xenopus embryo spinal cord and their role in the activation of swimming," The Journal of Physiology, vol. 348, pp. 527-543, 1984.

[49] N. Dale, "Excitatory synaptic drive for swimming mediated by amino acid receptors in the lamprey," Journal of Neuroscience, vol. 6, no. 9, pp. 2662-2675, 1986.

[50] M. D. Kvarta, R. M. Harris-Warrick, and B. R. Johnson, "Neuromodulator-evoked synaptic metaplasticity within a central pattern generator network," Journal of Neurophysiology, vol. 108, no. 10, pp. 2846-2856, 2012.

[51] R. F. Waldeck, A. Pereda, and D. S. Faber, "Properties and plasticity of paired-pulse depression at a central synapse," Journal of Neuroscience, vol. 20, no. 14, pp. 5312-5320, 2000.

[52] N. Harata, J. L. Pyle, A. M. Aravanis, M. Mozhayeva, E. T. Kavalali, and R. W. Tsien, "Limited numbers of recycling vesicles in small CNS nerve terminals: implications for neural signaling and vesicular cycling," Trends in Neurosciences, vol. 24, no. 11, pp. 637-643, 2001.

[53] J. M. Bower and L. B. Haberly, "Facilitating and nonfacilitating synapses on pyramidal cells: a correlation between physiology and morphology," Proceedings of the National Academy of Sciences of the United States of America, vol. 83, no. 4, pp. 1115-1119, 1986.

[54] L. E. Dobrunz and C. F. Stevens, "Heterogeneity of release probability, facilitation, and depletion at central synapses," Neuron, vol. 18, no. 6, pp. 995-1008, 1997.

[55] J. P. Pierce and L. M. Mendell, "Quantitative ultrastructure of Ia boutons in the ventral horn: scaling and positional relationships," Journal of Neuroscience, vol. 13, no. 11, pp. 4748-4763, 1993.

[56] T. Schikorski and C. F. Stevens, "Quantitative ultrastructural analysis of hippocampal excitatory synapses," The Journal of Neuroscience, vol. 17, no. 15, pp. 5858-5867, 1997.

[57] A. G. Millar, H. Bradacs, M. P. Charlton, and H. L. Atwood, "Inverse relationship between release probability and readily releasable vesicles in depressing and facilitating synapses," The Journal of Neuroscience, vol. 22, no. 22, pp. 9661-9667, 2002.

[58] R. S. Zucker and W. G. Regehr, "Short-term synaptic plasticity," Annual Review of Physiology, vol. 64, pp. 355-405, 2002.

[59] M. L. Mayer and G. L. Westbrook, "The physiology of excitatory amino acids in the vertebrate central nervous system," Progress in Neurobiology, vol. 28, no. 3, pp. 197-276, 1987.

[60] A. Qian, S. M. Antonov, and J. W. Johnson, "Modulation by permeant ions of $\mathrm{Mg}^{2+}$ inhibition of NMDA-activated wholecell currents in rat cortical neurons," Journal of Physiology, vol. 538, no. 1, pp. 65-77, 2002.

[61] S. Fusi and L. F. Abbott, "Limits on the memory storage capacity of bounded synapses," Nature Neuroscience, vol. 10, no. 4, pp. 485-493, 2007.

[62] D. Parker and S. Bevan, "Modulation of cellular and synaptic variability in the lamprey spinal cord," Journal of Neurophysiology, vol. 97, no. 1, pp. 44-56, 2007.

[63] F. Nadim and Y. Manor, "The role of short-term synaptic dynamics in motor control," Current Opinion in Neurobiology, vol. 10, no. 6, pp. 683-690, 2000.

[64] P. Miller, A. M. Zhabotinsky, J. E. Lisman, and X.-J. Wang, "The stability of a stochastic CaMKII switch: dependence on the number of enzyme molecules and protein turnover," PLoS biology., vol. 3, no. 4, article e107, 2005.

[65] L.-Y. Wang and L. K. Kaczmarek, "High-frequency firing helps replenish the readily releasable pool of synaptic vesicles," Nature, vol. 394, no. 6691, pp. 384-388, 1998.

[66] C. Rosenmund, A. Feltz, and G. L. Westbrook, "Calciumdependent inactivation of synaptic NMDA receptors in hippocampal neurons," Journal of Neurophysiology, vol. 73, no. 1, pp. 427-430, 1995.

[67] W. Ashby, "Principles of the self-organizing system," in Proceedings of the University of Illinois Symposium, Pergamon, Turkey, 1962.

[68] T. G. Buchman, "The community of the self," Nature, vol. 420, no. 6912, pp. 246-251, 2002.

[69] J. T. Buchanan, "Electrophysiological properties of identified classes of lamprey spinal neurons," Journal of Neurophysiology, vol. 70, no. 6, pp. 2313-2325, 1993.

[70] W. Zhang and S. Grillner, “The spinal 5-HT system contributes to the generation of fictive locomotion in lamprey," Brain Research, vol. 879, no. 1-2, pp. 188-192, 2000. 
[71] D. Parker and V. Srivastava, "Dynamic systems approaches and levels of analysis in the nervous system," Frontiers in Physiology, vol. 4, article 15, 2013.

[72] C. T. Pérez, R. H. Hill, and S. Grillner, "Endogenous tachykinin release contributes to the locomotor activity in lamprey," Journal of Neurophysiology, vol. 97, no. 5, pp. 3331-3339, 2007.

[73] L. Brodin, O. Shupliakov, V. A. Pieribone, J. Hellgren, and R. H. Hill, "The reticulospinal glutamate synapse in lamprey: plasticity and presynaptic variability," Journal of Neurophysiology, vol. 72, no. 2, pp. 592-604, 1994.

[74] J. T. Buchanan, "Identification of interneurons with contralateral, caudal axons in the lamprey spinal cord: synaptic interactions and morphology," Journal of Neurophysiology, vol. 47, no. 5, pp. 961-975, 1982.

[75] K. J. Dougherty and O. Kiehn, "Firing and cellular properties of V2a interneurons in the rodent spinal cord," Journal of Neuroscience, vol. 30, no. 1, pp. 24-37, 2010.

[76] C. A. Hinckley and L. Ziskind-Conhaim, "Electrical coupling between locomotor-related excitatory interneurons in the mammalian spinal cord," The Journal of Neuroscience, vol. 26, no. 33, pp. 8477-8483, 2006.

[77] W.-C. Li, A. Roberts, and S. R. Soffe, "Locomotor rhythm maintenance: electrical coupling among premotor excitatory interneurons in the brainstem and spinal cord of young Xenopus tadpoles," The Journal of Physiology, vol. 587, no. 8, pp. 16771693, 2009.

[78] S. Oleskevich, F. J. Alvarez, and B. Walmsley, "Glycinergic miniature synaptic currents and receptor cluster sizes differ between spinal cord interneurons," Journal of Neurophysiology, vol. 82, no. 1, pp. 312-319, 1999.

[79] W. Vandenberghe, V. P. Bindokas, R. J. Miller, W. Robberecht, and J. R. Brorson, "Subcellular localization of calciumpermeable AMPA receptors in spinal motoneurons," European Journal of Neuroscience, vol. 14, no. 2, pp. 305-314, 2001.

[80] S. A. Crone, K. A. Quinlan, L. Zagoraiou et al., "Genetic ablation of V2a ipsilateral interneurons disrupts left-right locomotor coordination in mammalian spinal cord," Neuron, vol. 60, no. 1, pp. 70-83, 2008.

[81] K. Ampatzis, J. Song, J. Ausborn, and A. El Manira, "Separate microcircuit modules of distinct V2a interneurons and motoneurons control the speed of locomotion," Neuron, vol. 83, no. 4, pp. 934-943, 2014.

[82] E. Marder, T. O’Leary, and S. Shruti, "Neuromodulation of circuits with variable parameters: single neurons and small circuits reveal principles of state-dependent and robust neuromodulation," Annual Review of Neuroscience, vol. 37, no. 1, pp. 329-346, 2014. 

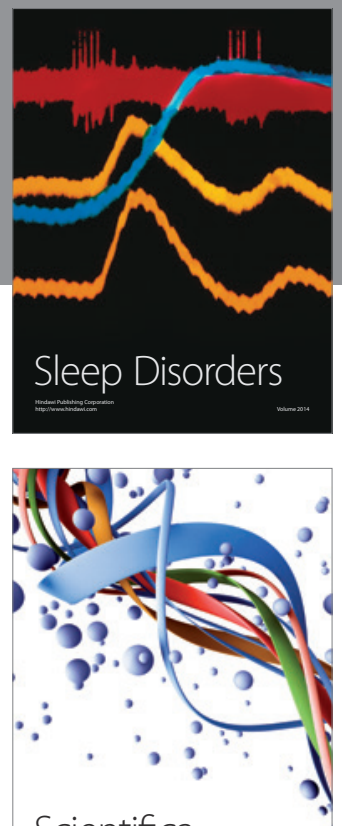

Scientifica
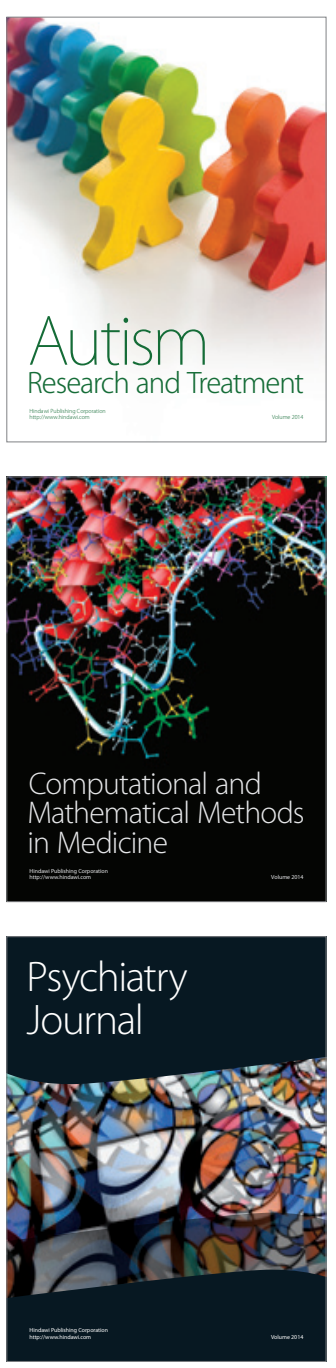
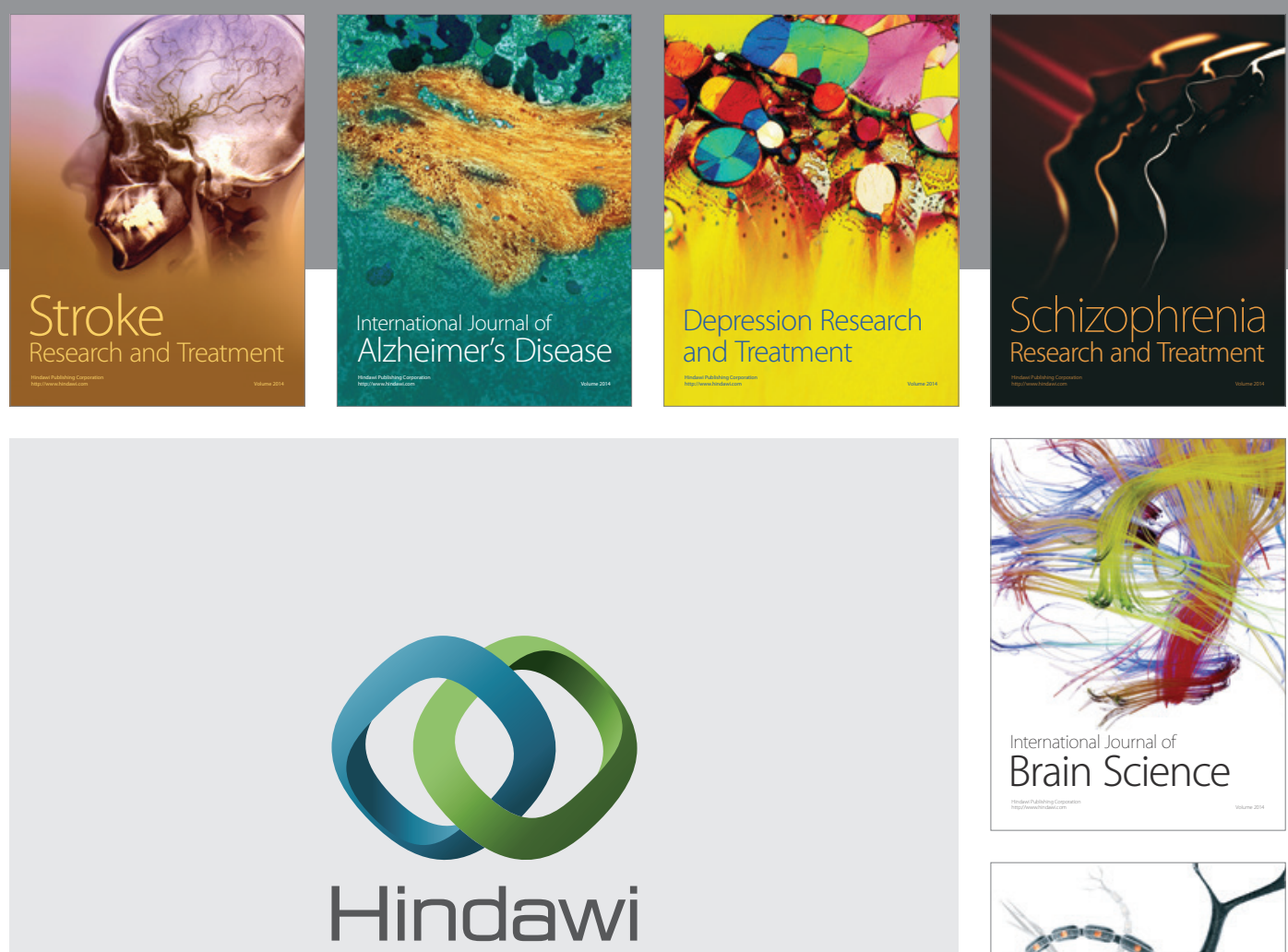

Submit your manuscripts at

http://www.hindawi.com
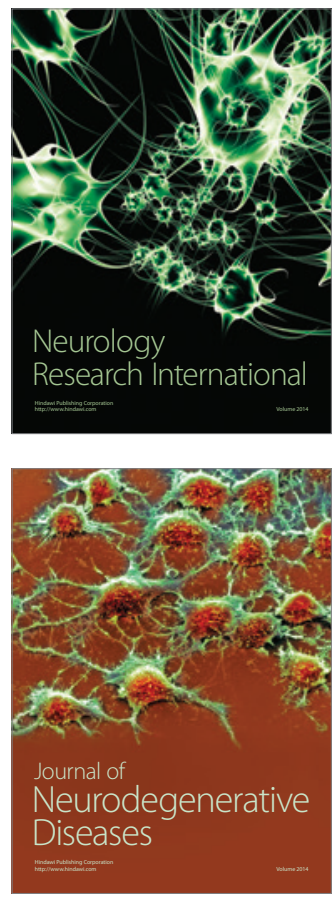

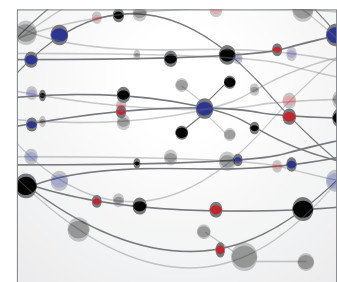

The Scientific World Journal
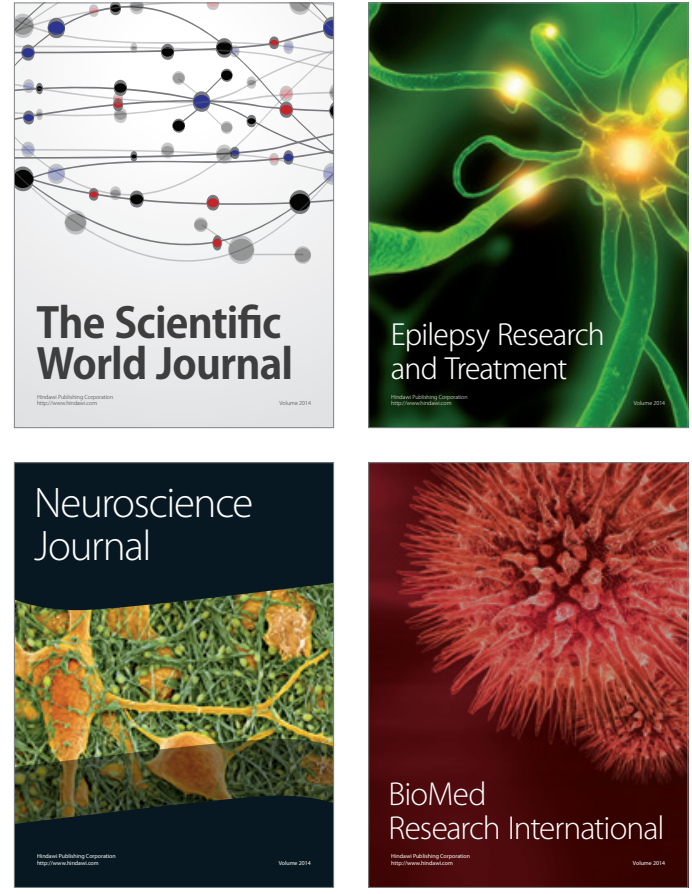

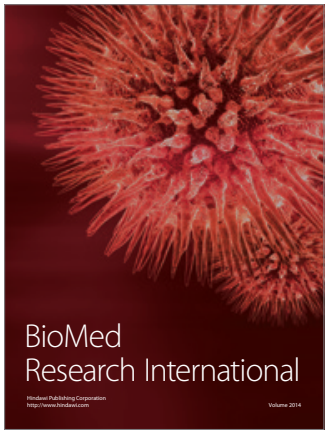

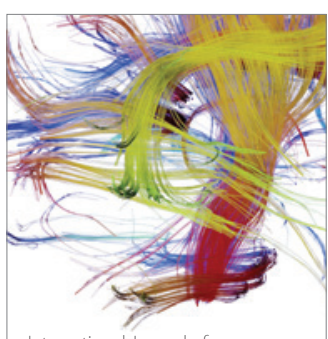

Brain Science

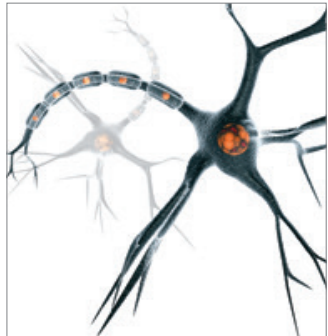

Neural Plasticity
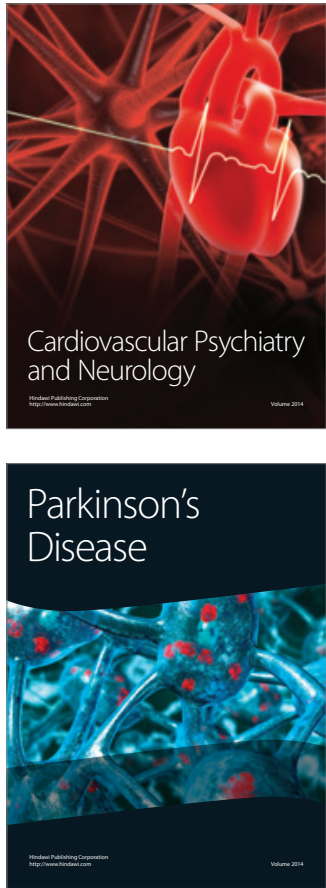